\title{
Key aspects in the strategic development of synthetic natural gas (BioSNG) supply chains
}

\author{
Andrés J. Calderón, Lazaros G. Papageorgiou* \\ Department of Chemical Engineering, UCL (University College London), London WC1E 7JE, \\ UK \\ ${ }^{*}$ Corresponding author. E-mail address: l.papageorgiou@ucl.ac.uk (L.G. Papageorgiou).
}

\begin{abstract}
This work investigates the impact of pretreatment technologies in the design of BioSNG supply chains at a regional and national scale. For this purpose, an optimisation-based framework is proposed to account for two possible routes for BioSNG production. The first route considers processing of raw biomass and production of BioSNG in integrated facilities. The second route consists of pretreatment technologies, transportation of intermediate products, and upgrading facilities. The main objective is to investigate the trade-off between capital investment and reduction of transportation costs, and their impact in the economic performance of a BioSNG supply chain. Moreover, the impact of government subsidisation is further investigated through a parametric analysis in which the tariff is varied from $£ 0 / M W h$ up to $£ 100 / M W h$. Finally, the major contributing factors in the design of BioSNG supply chains are identified through the implementation of a rigorous global sensitivity analysis (GSA). The results suggest that inclusion of pretreatment technologies improve considerably the economic performance, however, their impact is not enough to detach the development from government subsidisation which influences tremendously the possibility of a large scale deployment.
\end{abstract}




\section{Keywords}

28 Mixed integer linear programming; Synthetic natural gas (BioSNG); government subsidisation; Renewable obligation certificates (ROCs); Pretreatment technologies; Renewable resources.

\section{Introduction}

As the effects of climate change become more evident, the race for the decarbonisation of our energy systems has gained momentum thanks to concerted efforts between governments, private sectors, and scientific community. Initiatives such as the UN Climate Change Conference have paved the road for the nations to move towards a low-carbon economy. Different targets have been established in which renewable technologies play an important role. These targets are accompanied by policies that promote the utilisation of renewable technologies through different schemes such as subsidisation tariffs [1]. Over the last two decades, remarkable advances have been achieved in the broad spectrum of sustainable technologies for energy generation. For instance, costs of photovoltaic solar panels have been substantially reduced whereas the efficiency has been improved $[2,3]$. Likewise, the design of higher wind turbines expands the application of this technology to areas that were previously thought of as inadequate for wind energy [4]. These technologies have great potential to harness the decarbonisation of the power sector. On the other hand, the production of fuels from sustainable resources has been actively investigated for the decarbonisation of the transportation sector which in 2014 accounted for $25.5 \%$ of the total greenhouse gas (GHG) emissions in Europe [5].

Several routes have been developed for the production of transportation fuels, e.g. gasoline, diesel, methane, and ethanol, from different sources such as wood, grass, municipal waste, agricultural residues, etc [6-11]. Nonetheless, these technologies face important technological and operational challenges that should be addressed for largescale developments. One of the technological challenges is the variability of the chemical and physical properties of the feedstocks. Therefore, the development of robust and flexible technologies is sought after since the heterogeneity of the feedstocks can affect the efficiency of the process. Moreover, capital investments are very high in comparison to 
conventional technologies. For example, in 2011 the production of power with a combined cycle gas turbine requires an investment of $€ 800 / \mathrm{kw}$ whereas power generation from biomass combustion was estimated in $€ 2500 / \mathrm{kw}$, around 3 -fold times the conventional technology [12]. Among operational challenges, securing a reliable and low-cost supply of feedstocks is crucial. However, feedstocks are normally dispersed within a region and their energy content (energy density) is comparatively low to other conventional energy sources. For instance, the low heat value (LHV) of soft wood is $12 \mathrm{MJ} / \mathrm{kg}$ whereas for coal the LHV ranges between $25 \mathrm{MJ} / \mathrm{kg}-30 \mathrm{MJ} / \mathrm{kg}$ [13]. This leads to subutilisation of transportation capacity which translates into higher transportation costs. The scientific community has proposed the implementation of pretreatment technologies as one way of decreasing transportation costs. This is achieved by preprocessing raw materials into higher energy density carriers that require of smaller infrastructure for their transportation [14-16] and further processing. An additional benefit of pretreatment technologies is the homogenisation of raw materials which may improve the efficiency of a following process such as gasification [17]. Nonetheless, the implementation of these technologies should be carefully considered so that the associated investments do not offset the potential savings in transportation costs.

Different mechanical and thermal processes have been developed for biomass pretreatment. For instance, pelletisation is a mechanical process in which the biomass is dried and pressed to produce cylindrical pieces with higher energy density. Feedstocks such as sawdust and energy crops benefit from this process as their density is very low for transportation [18]. The global efficiency varies between 96 to $99 \%$ based on low heating value [19]. Pyrolysis of biomass is a thermal process that has been proposed as an intermediate step for production of biofuels and/or different chemicals [8,20-22]. Depending on the type of reactor different products can be obtained such as bio-oil and bio-char $[7,8]$. For example, biomass and sand are fed into a rotating cone reactor to produce pyrolysis vapours that are subsequently condensed to obtain bio-oil. The global efficiency of this process is $73 \%$ based on low heating value [14]. Bio-slurry (bio-oil + biochar), on the other hand, can be produced in a fluidised bed reactor in which biomass reacts with air to produce char and vapours. The pyrolysis vapours are condensed and 
mixed with char to produce bio-slurry. The efficiency of this process is around 93\% based on low heating value [14]. Torrefaction is a thermal pretreatment technology performed at atmospheric pressure in absence of oxygen. It has been reported that torrefaction benefits the production of synthetic natural gas from woody feedstocks [23]. Torrefaction is a very promising technology due to its high process efficiency. When this technology is combined with pelletisation (TOP), the energy content of the product can be between 20.4-22.7 GJ/ton and the global efficiency of the process is 96\% [14]. The selection of pretreatment technologies depends on the nature of the feedstock and the application of the energy carrier. For example, pyrolysis is adequate for production of diesel from lignocellulosic materials [24], whereas torrefaction is preferred if a gasification step follows [25].

Due to the potential shown in different studies, pretreatment technologies have been considered as part of the design of integrated facilities for production of transportation fuels and chemicals. For instance, pyrolysis and torrefaction have been investigated via thermo-economic analysis for the design of a process for the production of synthetic natural gas from sustainable resources (BioSNG) [26] as well as for the production of liquid fuels $[27,28]$. Moreover, optimisation techniques have been implemented for the synthesis of integrated biorefineries in which pretreatment technologies play an important role [29]. Different applications have been addressed such as polygeneration of BioSNG [30], production of gasoline, diesel, and jet fuel [31,32], production of Fisher-Tropsch liquids and acids such as acetic, lactic, and levulinic [33]. Furthermore, the substantial progress achieved in the design of sustainable supply chains [34-37] has served as basis to investigate the relevance of pretreatment technologies a supply chain context. Wright and Brown (2008) [38] addressed the production of Fisher-Tropsch liquids through centralised and distributed schemes. It was found that after certain production capacity, distributed biomass pretreatment via pyrolysis for production of bio-oil and subsequent processing in a centralised facility offers advantages over a completely centralised scheme. On the other hand, Uslu et al. (2008) [16] investigated the effect of pretreatment technologies on an international supply chain via techno-economic analysis. The authors concluded that distributed pretreatment based on torrefaction combined with pelletisation presents advantages over pelletisation and pyrolysis. Dunnett et al. (2008) [39] developed a mixed- 
integer linear programming (MILP) problem to investigate the concept of centralised vs distributed schemes for the production of ethanol. In their study, the pretreatment stage was implemented to produce intermediate ethanol concentrations. This concept was further investigated in which the decentralised production of biofuels is addressed using preprocessing hubs [40] and pyrolysis as pretreatment technology [41,42]. Finally, You and Wang (2011) [43] proposed a superstructure for production of cellulosic biofuels in which the concept of upgrading facilities is introduced in the optimisation framework. The authors discus the design of supply chains for the production of gasoline and diesel and conclude that pretreatment technologies such as torrefaction and pyrolysis benefit the economic performance.

In this work, we discuss the relevance of pretreatment technologies in the design of BioSNG supply chains. For this purpose, an optimisation framework previously presented by the authors is revisited [44]. The framework is extended based on the concept introduced by You and Wang (2011) [43] in order to investigate the installation of pretreatment technologies and upgrading facilities in the design of BioSNG supply chains. Moreover, the proposed model is used to examine different government subsidisation levels and their impact on the development of BioSNG supply chains. Finally, a global sensitivity analysis (GSA) approach is implemented in order to quantify the effect of uncertainties associated to input parameters and identify those that have the major impact.

The rest of the paper is organised as follows: in section 2 we present the problem statement along with a simplified superstructure showing the main components of a BioSNG supply chain. Section 3 presents the new mathematical formulation related to installation and operation of pretreatment and upgrading technologies. The complete formulation can be found in Appendix A of supporting information. Section 4 introduces a case study for the UK, which is based on the case presented in Calderón et al. (2017) [44]. The optimisation results are discussed in section 5. Finally, the contributions of this work are discussed in section 6 . 


\section{Problem statement}

The developments of BioSNG supply chains by means of integrated technologies have been addressed in a previous work by the authors [44]. In this section, we present an extension of the generic BioSNG supply chain by considering two different conversion routes to account for distributed or centralised production schemes as shown in Figure 1.

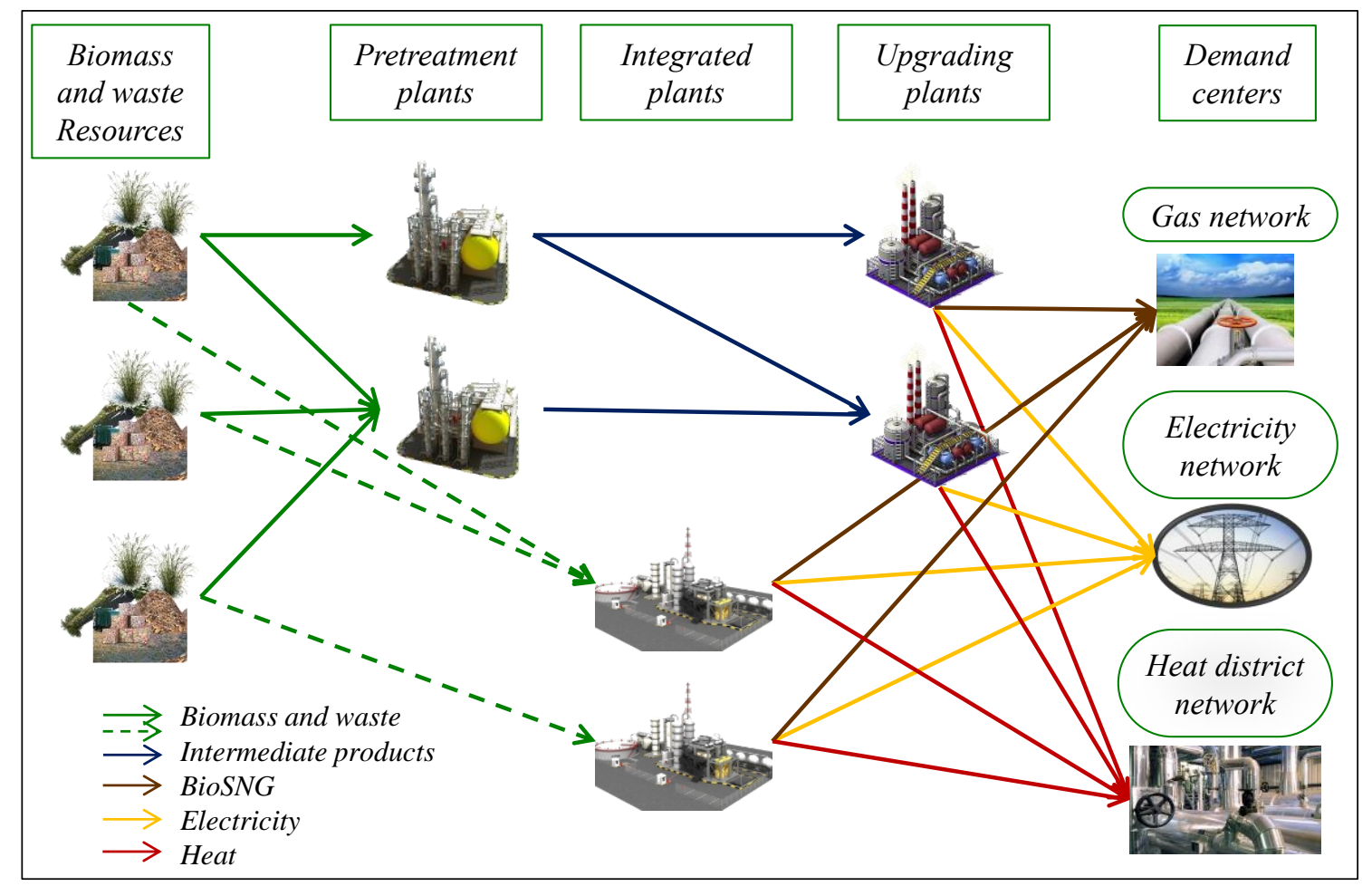

Figure 1. Generic BioSNG supply chain

For the centralised scheme, integrated plants process raw feedstock and convert it into final products, BioSNG, heat and/or power. For the distributed arrangement, the raw feedstock is sent first to a pretreatment facility where it is processed to obtain intermediate products with higher energy density. The intermediate products are then transported to upgrading plants for their conversion into final products. The technologies included for pretreatment plants are pelletisation, torrefaction-pelletisation (TOP), and pyrolysis which can produce intermediate products such as bio-oil and bio-slurry, torrefied biomass, and pellets, respectively. For integrated plants and upgrading plants the chosen technology is gasification. 


\section{Mathematical formulation}

160

In this section, we present an extension of the optimisation framework previously

161 presented by the authors. The new features of the model allow to investigate the impact of

162 pretreatment technologies on the strategic design and planning of BioSNG supply chains.

163 The complete optimisation framework is presented in Appendix A in supporting

164 information.

165 Nomenclature

\section{$166 \quad$ Indices}

$\begin{array}{ll}f & \text { Feedstocks } \\ g, g^{\prime} & \text { Regions } \\ i & \text { Resources } \\ k & \text { Technologies } \\ l & \text { Transportation modes } \\ h & \text { Intermediate products } \\ p & \text { Final products } \\ s & \text { Segments for cost linearisation } \\ t, t^{\prime} & \text { Time periods }\end{array}$

167

168 Sets

F

$F^{a}$

$F^{e}$

I

$K^{I}$

$K^{P}$

$K^{U}$

$P$

$F_{k}$

$H_{k}$
Set of feedstocks, $F=F^{a} \cup F^{e}$

Set of available feedstocks

Set of new energy crops

Set of resources (feedstocks and final products), $I=F \cup P$

Set of technologies for integrated facilities

Set of technologies for pretreatment facilities

Set of technologies for upgrading facilities

Set of final products

Set of feedstocks $f$ that can be processed by technologies $k$

Set of intermediate products $h$ that can be processed by technologies $k$ 
$G_{z}$

$\eta_{\text {igg } l}$

169

170

$A v f$

$C f$

$\alpha$

$\mu$

171

172
Set of regions $g$ with injection points corresponding to a local distribution zone $\mathrm{z}$

Set of feasible transport links for each resource $i$ between region $g$ and $g^{\prime}$ via transport mode $l$

Availability factor for renewable energy plants

Capacity factor for renewable energy plants

Operating period in a year [hr year-1]

Steam to power generation efficiency

Independent term of the linearised Capex curve for integrated plants processing feedstock $f$ with technology $k$ at each segment $s[€ \mathrm{~m}]$

$a P R_{f k s} \quad$ Independent term of the linearised Capex curve for pretreatment plants processing feedstock $f$ with technology $k$ at each segment $s[\mathrm{Em}]$

$a U P_{h k s}$

Independent term of the linearised Capex curve for upgrading plants processing intermediate product $h$ with technology $k$ at each segment $s[\mathrm{Em}]$

$b I N_{f k s}$

Slope of the linearised Capex curve for an integrated plant processing feedstock $f$ with technology $k$ at each segment $s[E m$ $\mathrm{MW}^{-1}$ ]

$b P R_{f k s} \quad$ Slope of the linearised Capex curve for pretreatment plants processing feedstock $f$ with technology $k$ at each segment $s[€ \mathrm{~m}$ $\left.\mathrm{MW}^{-1}\right]$

$b U P_{h k s} \quad$ Slope of the linearised Capex curve for upgrading plants processing intermediate product $h$ with technology $k$ at each segment $s\left[E m \mathrm{MW}^{-1}\right]$

CMax $_{k s} \quad$ Maximum capacity of technology $k$ at each linearisation segment $s$ of the Capex curve [MW]

$\mathrm{CMin}_{k s} \quad$ Minimum capacity of technology $k$ at each linearisation segment $s$ of the Capex curve [MW]

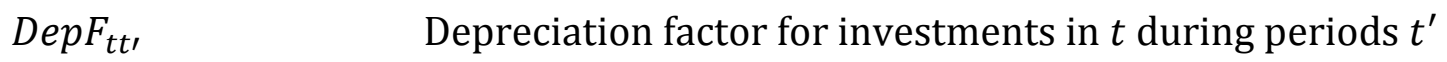



FxOpIN fkt
Fixed costs for operation and maintenance for an integrated plant processing feedstock $f$ via technology $k$ in time period $t$ [Em year $\left.{ }^{-1}\right]$
$F x O p P R_{f k t} \quad$ Fixed costs for operation and maintenance for pretreatment plants processing feedstock $f$ via technology $k$ in time period $t$ [Em year-1]
FxOpUP $P_{h t}$
$\operatorname{VrOpIN}_{f k t}$
$\operatorname{VrOpPR}_{f k t}$
$\operatorname{VrOpUP} P_{h k}$
$\operatorname{VrTC} C_{i}^{L o c}$
$\operatorname{VrTC} C_{i l}^{\text {Reg }}$
$\beta I N_{f k t}$
$\beta P R_{f k t}$
$\beta U P_{h k t}$
Fixed costs for operation and maintenance for upgrading plants processing intermediate product $h$ via technology $k$ in time period $t\left[£\right.$ m year $\left.{ }^{-1}\right]$
Variable costs of operation and maintenance for integrated plants processing feedstock $f$ using technology $k$ in time period $t\left[E \mathrm{~m} \mathrm{GWh}^{-1}\right]$
Variable costs of operation and maintenance for pretreatment plants processing feedstock $f$ using technology $k$ in time period $t\left[E \mathrm{~m} \mathrm{GWh}^{-1}\right]$
Variable costs of operation and maintenance for upgrading plants processing intermediate product $h$ using technology $k$ in time period $t\left[\mathrm{Em} \mathrm{GWh}^{-1}\right]$
Variable local transport costs for resources $i\left[€ \mathrm{Ton}^{-1} \mathrm{~km}^{-1}\right]$
Variable regional transport costs for resources $i$ via mode $l[\epsilon$ Ton $^{-1} \mathrm{~km}^{-1}$ ]
Efficiency of integrated plants processing feedstock $f$ with technology $k$ to produce $p$
Efficiency of pretreatment plants processing feedstock $f$ with technology $k$ to produce $p$
Efficiency of upgrading plants processing intermediate product $h$ with technology $k$ to produce $p$

\section{Positive continuous variables}

CAPEX $X_{t}$

CAPEX_EC

CAPEX_IN

CAPEX_PR

CAPEX_UP

CAPEX_TR
Total investment cost for the supply chain in time period $t[E \mathrm{~m}]$

Total investment cost for new energy crops in time period $t$ [Em]

Total investment cost of integrated plants in time period $\mathrm{t}$ [ $\mathrm{Em}]$

Total investment cost of pretreatment plants in time period $t$ [Em]

Total investment cost of upgrading plants in time period $\mathrm{t}[\mathrm{Em}]$

Total investment cost for new BioSNG transport facilities time 
period $t[E \mathrm{~m}]$
CAPIN $_{\text {fkgts }} \quad$ Initial installed capacity for an integrated plant processing feedstock $f$ using technology $k$ in region $g$ and and is available in time period $t$ at segment $s$ [MW]
$C A P P R_{\text {fkgts }} \quad$ Initial installed capacity for a pretreatment plant processing feedstock $f$ using technology $k$ in region $g$ and and is available in time period $t$ at segment $s$ [MW]
CAPUP $_{\text {hkgts }} \quad$ Initial installed capacity for an upgrading plant processing intermediate product $h$ using technology $k$ in region $g$ and and is available in time period $t$ at segment $s$ [MW]
$D_{\text {igt }}$
$D E P_{t t \prime}$
$D I N_{f k g t}$
$D P R_{f k g t}$
DUP $P_{h k g t}$
$F C_{t}$
$P_{i g t}$
$P C_{t}$
$P_{\text {IN }}$ fpgt
PPR fkpgt $_{\text {t }}$
Demand for resource $i$ in region $g$ in time period $t$ [GWh year-1]
Depreciation for investments in $t$ during periods $t^{\prime}$ [Em year-1]
Demand of an integrated plant processing feedstock $f$ with technology $k$ in region $g$ in time period $t$ [GWh year-1]
Demand of a pretreatment plant processing feedstock $f$ with technology $k$ in region $g$ in time period $t$ [GWh year-1]
Demand of an upgrading plant processing intermediate product $h$ with technology $k$ in region $g$ in time period $t$ [GWh year-1]
Total feedstock cost in time period $t$ [ $E$ m year $\left.{ }^{-1}\right]$
Production rate of product $i$ in region $g$ in time period $t$ [GWh year-1 $^{-1}$
Total production cost in time period $t\left[\mathrm{Em}_{\mathrm{mear}}{ }^{-1}\right]$
Production rate at an integrated plant processing feedstock $f$ with technology $k$ to produce $p$ in region $g$ in time period $t$ [GWh year-1]
Production rate at a pretreatment plant processing feedstock $f$ with technology $k$ to produce $p$ in region $g$ in time period $t$ [GWh year-1]

PUP hkpgt

$T A X_{t}$

ToCAPIN $_{\text {fkgt }}$

$T o C A P P R_{f k g t}$

Production rate at an upgrading plant processing intermediate product $h$ with technology $k$ to produce $p$ in region $g$ in time period $t$ [GWh year-1]

Total taxes in time period $t$ [ $€ \mathrm{~m}$ year $\left.{ }^{-1}\right]$

Total capacity of an integrated plant processing feedstock $f$ in region $g$ and using technology $k$ that is available in time period $t[\mathrm{MW}]$

Total capacity of a pretreatment plant processing feedstock $f$ in region $g$ and using technology $k$ that is available in time period $t[\mathrm{MW}]$ 
ToCAPUP $P_{\text {hkt }} \quad$ Total capacity of an upgrading plant processing intermediate product $h$ in region $g$ and using technology $k$ that is available in time period $t[\mathrm{MW}]$

175

176

$C f_{t}$

PROFIT $_{t}$

177

178

\section{Binary variables}

AvIN $N_{\text {fkgts }}$

$A v P R_{\text {fkgts }}$

AvUP $P_{h k g t s}$

$\delta I N_{\text {fkgts }}$

$\delta P R_{\text {fkgts }}$

$\delta U P_{\text {hkgts }}$
1 if an integrated plant processing feedstock $f$ using technology $k$ and located in region $g$ is operating in time period $t$ with a capacity delimited by a segment $s, 0$ otherwise.

1 if a pretreatment plant processing feedstock $f$ using technology $k$ and located in region $g$ is operating in time period $t$ with a capacity delimited by a segment $s, 0$ otherwise.

1 if an upgrading plant processing intermediate product $h$ using technology $k$ and located in region $g$ is operating in time period $t$ with a capacity delimited by a segment $s, 0$ otherwise.

1 if an integrated plant processing feedstock $f$ using technology $k$ in region $g$ is installed in time period $t$ with a capacity delimited by a segment $s, 0$ otherwise.

1 if a pretreatment plant processing feedstock $f$ using technology $k$ in region $g$ is installed in time period $t$ with a capacity delimited by a segment $s, 0$ otherwise.

1 if an upgrading plant processing intermediate product $h$ using technology $k$ in region $g$ is installed in time period $t$ with a capacity delimited by a segment $s, 0$ otherwise.

\subsection{Objective function}

\subsubsection{Capital investments}

Capital expenditures, CAPEX $_{t}$, are calculated as the summation of the investment in

183 integrated facilities, CAPEX_IN $\mathrm{t}$, investment in upgrading facilities, CAPEX_UP, investment 184 in pretreatment facilities, CAPEX_PR $\mathrm{t}_{\mathrm{t}}$ investment in infrastructure for BioSNG 
transportation, CAPEX_TR $\mathrm{t}_{\mathrm{t}}$, and investment in new energy crops for BioSNG production, CAPEX_EC $t$, as shown in Equation (1).

$$
C A P E X_{t}=C A P E X_{-} I N_{t}+C A P E X_{-} U P_{t}+C A P E X_{-} P R_{t}+C A P E X_{-} T R_{t}+C A P E X_{-} E C_{t} \quad \forall t
$$

\subsubsection{Cash flow and depreciation}

Cash flow is defined as the profit before taxes, PROFIT , plus depreciation of assets, $D E P_{t \prime}$, minus taxes, $T A X_{t}$, as presented in Equation (2).

$$
C F_{t}=P R O F I T_{t}+\sum_{t^{\prime}} D E P_{t^{\prime} t}-T A X_{t} \quad \forall t
$$

The linear method is used to calculate the depreciation, $D E P_{t t}$, as a function of capital expenditures using a given depreciation rate, $D e p F_{t t}$, as expressed in Equation (3). $D E P_{t t}$, represents the depreciation during period $t^{\prime}$ for investments made in a previous period $t$ :

$$
D E P_{t t^{\prime}}=D e p F_{t t \prime}\left(C A P E X_{-} I N_{t}+C A P E X_{-} U P_{t}+C A P E X_{-} P R_{t}+C A P E X_{-} T R_{t}\right) \quad \forall t, t^{\prime}
$$

The investment costs related to energy crops (pre-planting and establishment costs), CAPEX_EC , are considered non-depreciable.

\subsection{Production of intermediate and final products}

For the production of intermediate and final products, three different conversion technologies are considered: Integrated technologies, pre-treatment technologies and upgrading technologies. The integrated technologies represent a possible route for the production of final products. In this case, the biomass is pre-processed and converted to final products in the same facilities; this implies higher costs related to the transportation of raw biomass. A second optional route is to decouple the integrated process into two processes where the biomass is sent first to pretreatment conversion plants to generate intermediate products with higher energy density. The intermediate products are sent to upgrading conversion plants where the final products are obtained. This route allows to reduce transportation costs, however higher capital investments are required. The production of final products, $P_{p g t}$, is equal to the production from integrated plants plus the production from upgrading plants, as depicted in Equation (4) 


$$
P_{p g t}=\sum_{k \in K^{I}} \sum_{f \in F_{k}} P I N_{f k p g t}+\sum_{k \in K^{U}} \sum_{h} P U P_{h k p g t} \quad \forall p, g, t
$$

PIN $_{\text {fkpgt }}$ indicates the production of a potential integrated plant processing feedstock $f$ with technology $k \in K^{I}$ to produce $p$ in region $g$ during time period $t$. Set $F_{k}$ contains connections between feedstocks $f$ that can be processed with technologies $k$. $P U P_{h k p g t}$ refers to the production of a potential upgrading plant processing intermediate product $h$ with technology $k \in K^{U}$ to produce $p$ in region $g$ during time period $t . K^{I}$ and $K^{U}$ are sets for integrated and upgrading technologies, respectively. It is assumed that intermediate products can be processed by any upgrading technology.

The regional production of intermediate products, $P_{h g t}$, is related to the production in pretreatment facilities, $P P R_{f k h g t}$, by means of Equation (5):

$$
P_{h g t}=\sum_{k \in K^{P} \cap k: h \in H_{k}} \sum_{f \in F_{k}} P P R_{f k h g t} \forall h, g, t
$$

Set $H_{k}$ contains connections between intermediate products $h$ that can be processed with technologies $k$. No energy integration is considered for pretreatment plants. Therefore, only one balance is enough to model the process as described in Equation (6):

$$
P P R_{f k h g t}=\beta P R_{f k h} D P R_{f k g t} \quad \forall k \in K^{P}, f \in F_{k}, h \in H_{k}, g, t
$$

where $\beta P R_{f k h}$ corresponds to the efficiency of producing $h$ from $f$ using technology $k$, and $D P R_{f k g t}$ is the local demand of a pretreatment plant. Finally, energy integration is considered for upgrading plants for the production of heat and power. Consequently, two equations are formulated corresponding to the BioSNG production and the global balance of the plant. The BioSNG production rate, $P U P_{h k, b i o s n g, g t}$, is calculated as stated in Equation (7):

$$
P U P_{h k, b i o s n g, g t}=\beta U P_{h k, b i o s n g} D U P_{h k g t} \quad \forall h, k \in K^{U}, g, t
$$

where $\beta U P_{h k, b i o s n g}$ is the efficiency of conversion of intermediate products to BioSNG, and $D U P_{h k g t}$ is the local demand for intermediate products. The global balance of upgrading plants is equivalent to the balance for integrated plants as shown in Equation (8). 


$$
\frac{P U P_{h k, p o w e r, g t}}{\mu}+P U P_{h k, h e a t, g t} \leq \beta U P_{h k, h e a t} * D U P_{h k g t} \quad \forall h, k, g, t
$$

\subsection{Demand constraints}

\subsubsection{Demand of feedstocks}

The regional demand of feedstocks, $D_{f g t}$, is calculated as shown in Equation (9):

$$
D_{f g t}=\sum_{k \in K^{I} \cap k: f \in F_{k}} D I N_{f k g t}+\sum_{k \in K^{P} \cap k: f \in F_{k}} D P R_{f k g t} \quad \forall f, g, t
$$

where the $D I N_{f k g t}$ and $D P R_{f k g t}$ refer to the demand of feedstocks in integrated and pretreatment facilities, respectively.

\subsubsection{Demand of intermediate products}

The total regional demand for intermediate products; $D_{h g t}$, is calculated based on the summation of the demand by upgrading plants in order to generate final products. This is expressed as shown in Equation (10).

$$
D_{h g t}=\sum_{k \in K^{U}} D U P_{h k g t} \quad \forall h, g, t
$$

\subsection{Capital investments}

\subsubsection{Piecewise linearisation for pretreatment plants}

The same strategy for linearisation is used for pretreatment plants. The segments are limited by $C M i n_{k s}$ and $C M a x_{k s}$. CAPPR fkgts is the new installed capacity of pretreatment plants in region $g$, using technology $k$ during period $t$.

$$
\operatorname{CMin}_{k s} * \delta P R_{f k g t s} \leq C A P P R_{f k g t s} \leq \operatorname{CMax}_{k s} * \delta P R_{f k g t s} \quad \forall k \in K^{P}, f \in F_{k}, g, t, s
$$

$\delta P R_{f k g t s}$ is a binary variable that equals 1 if a plant is installed using technology $k$ for processing feedstock $f$ in period $t$ with a capacity defined by the segment $S$. Only one segment can be activated, and only one pretreatment plant is allowed to be installed for each type of feedstock in region $g$. These conditions are modelled through Equations (12) and (13), respectively. 


$$
\begin{aligned}
& \sum_{s} \delta P R_{f k g t s} \leq 1 \quad \forall k \in K^{P}, f \in F_{k}, g, t \\
& \sum_{s} \sum_{k \in K^{P} \cap k: f \in F_{k}} \delta P R_{f k g t s} \leq 1 \quad \forall f, g, t
\end{aligned}
$$
254 in Equation (15).

$$
D P R_{f k g t} \leq C f * A v f * \alpha * T o C A P P R_{f k g t} \quad \forall k \in K^{P}, f \in F_{k}, g, t
$$

255 256

The total current capacity, $T o C A P P R_{f k g t}$, is equal to the newly installed capacity, $C A P P R_{f k g t s}$, plus the previous capacity, ToCAPPR $R_{f k g, t-1}$. This condition is represented by Equation (14):

$$
\operatorname{ToCAPPR}_{f k g t}=\operatorname{ToCAPPR}_{f k g, t-1}+\sum_{s} C A P P R_{f k g t s} \quad \forall k \in K^{P}, f \in F_{k}, g, t
$$

The demand of a pretreatment plant, $D P R_{f k g t}$, is limited by the current installed capacity, $T o C A P P R_{f k g t}$, the capacity factor, $C f$, and the availability factor, $A v f$, as shown in

Finally, the total investment cost, $C A P E X_{-} P R_{t}$, is calculated as shown in Equation (16):

$$
C A P E X_{-} P R_{t}=\sum_{k \in K^{P}, g s} \sum_{f \in F_{k}}\left(b P R_{f k s} * \delta P R_{f k g t s}+a P R_{f k s} * C A P P R_{f k g t s}\right) \quad \forall t
$$

Where $a P R_{f k s}$ and $b P R_{f k s}$ are parameters that represent variable and fixed investment costs. This information is obtained from the linearisation of the corresponding investment cost curve.

\subsubsection{Piecewise linearisation for upgrading plants}

The capital investment costs linearisation for upgrading plants is shown in Equation (17). $C A P U P_{\text {hkgts }}$ refers to the newly installed capacity during period $t$ in region $g$, using technology $k$ available in time period $t$.

$$
\operatorname{CMin}_{k s} * \delta U P_{\text {hkgts }} \leq C A P U P_{h k g t s} \leq \operatorname{CMax}_{k s} * \delta U P_{\text {hkgts }} \quad \forall k \in K^{U}, h, g, t, s
$$


$\delta U P_{h k g t s}$ is a binary variable that equals 1 in case an upgrading plant with

$$
C A P E X_{-} U P_{t}=\sum_{k \in K^{U}, g s} \sum_{h}\left(b U P_{h k s} * \delta U P_{h k g t s}+a U P_{h k s} * C A P U P_{h k g t s}\right) \quad \forall t
$$

277 where $a U P_{h k s}$ and $b U P_{h k s}$ are parameters related to the linearisation of the investment 278 costs curve.

The total current capacity, ToCAPUP ${ }_{h k g t}$, is equal to the newly installed capacity, CAPUP $P_{h k g t s}$, plus the previous capacity, ToCAPUP $P_{h k g, t-1}$. This condition is represented by Equation (20):

$$
T o C A P U P_{h k g t}=T o C A P U P_{h k g, t-1}+\sum_{s} C A P U P_{h k g t s} \quad \forall k \in K^{U}, h, g, t
$$

Similarly, the demand of intermediate products in an upgrading plant, $D U P_{h k g t}$, is limited by the current installed capacity, ToCAPUP ${ }_{h k g t}$, the capacity factor, $C f$, and the availability factor, $A v f$, as shown in in Equation (15).

$$
D U P_{h k g t} \leq C f * A v f * \alpha * T o C A P U P_{h k g t} \quad \forall k \in K^{U}, h, g, t
$$

Finally, the total investment cost, $C A P E X_{-} U P_{t}$, is calculated as shown in Equation (22):

278 . costs curve. 


\subsection{Production costs}

The total production cost, $P C_{t}$, is divided into fixed and variable costs. Fixed costs are independent of the output level of a plant and often include insurance, rent, salaries, etc. On the other hand, variable costs such as inventory, utilities, packaging, etc. depend proportionally on the actual production of a plant. This is expressed mathematically in Equation (23):

$$
\begin{aligned}
& P C_{t}=\sum_{k \in K^{I}, g} \sum_{f \in F_{k}}\left(F x O p I N_{f k t} * A v I N_{f k g t}+\operatorname{VrOpIN}_{f k s} * \operatorname{PIN}_{f k g, b i o s n g, t}\right) \\
& +\sum_{k \in K^{P}, g} \sum_{f \in F_{k}} \sum_{h \in H_{k}}\left(F x O p P R_{f k t} * A v P R_{f k g t}+V r O p P R_{f k s} * P P R_{f k g h t}\right) \\
& +\sum_{k \in K^{U}, g} \sum_{h}\left(F x O p U P_{h k t} * A v U P_{h k g t}+V r O p U P_{h k s} * P U P_{h k g, b i o s n g, t}\right) \forall t
\end{aligned}
$$

The parameters $F x O p I N_{f k t}, F x O p P R_{f k t}$, and FxOpUP $P_{h k t}$ refer to fixed costs for integrated plants, pretreatment plants, and upgrading plants, respectively. The fixed costs are activated accordingly by the availability variables $A v I N_{f k g t}, A v P R_{f k g t}$, and $A v U P_{h k g t}$, which correspond to binary variables. Finally, $\operatorname{VrOpIN}{ }_{f k s}, \operatorname{VrOpP} R_{f k s}$, and $\operatorname{VrOpUP} P_{h k s}$ designate the respective variable costs for integrated, pretreatment plants, and upgrading plants, respectively. The availability variables are related to installation variables by means of Equations (24) and (25) for integrated plants:

$$
\begin{aligned}
& A v I N_{f k g t} \geq \sum_{s} \delta I N_{f k g t s} \quad \forall k \in K^{I}, f \in F_{k}, g, t \\
& A v I N_{f k g t} \geq A v I N_{f k g, t-1} \quad \forall k \in K^{I}, f \in F_{k}, g, t
\end{aligned}
$$

Analogous equations are included for pretreatment plants (see Equations (26)-(27)) and upgrading plants (see Equations (28)-(29)):

$$
\begin{aligned}
& A v P R_{f k g t} \geq \sum_{s} \delta P R_{f k g t s} \quad \forall k \in K^{P}, f \in F_{k}, g, t \\
& A v P R_{f k g t} \geq A v P R_{f k g, t-1} \quad \forall k \in K^{P}, f \in F_{k}, g, t
\end{aligned}
$$




$$
\begin{aligned}
& A v U P_{h k g t} \geq \sum_{s} \delta U P_{h k g t s} \quad \forall k \in K^{U}, h \in H_{k}, g, t \\
& A v U P_{h k g t} \geq A v U P_{h k g, t-1} \quad \forall k \in K^{U}, h \in H_{k}, g, t
\end{aligned}
$$

2944 Case study

295

296

297

298

299

300

301

302

303

304

305

306

307

308

309

310

311

312

313

314

315

316

317

318

319

The role of pretreatment technologies in the development of BioSNG supply chains is addressed through a case study based on the UK. The planning horizon is 20 years divided into four 5-year periods. The UK is divided in 35 regions based on level 2 of the Nomenclature of Territorial Units for Statistics (NUTS2) [45] (see Appendix B in supporting information). Four feedstocks are included as potential sources for BioSNG production: woody biomass, straw, residual waste, and miscanthus. The aforementioned feedstocks have been identified in different studies as the most likely materials to be used in the UK in case of developing gasification-based projects [46,47]. Regarding the gasification process, several technologies are available or in developing stage such as: Entrained Flow, Circulating Fluidized Bed (CFB) reactor, and allothermal (indirect) gasification. Among them, allothermal gasification presents comparatively higher efficiencies [48] for gasification of wood. The efficiencies have been reported to be $54 \%$ for Entrained Flow, $58 \%$ for $\mathrm{CFB}$, and up to $67 \%$ for allothermal gasification [49]. Accordingly, the allothermalbased gasification process called "MILENA", which is being developed by the Energy research Centre of the Netherlands (ECN), will be adopted in this study as the main technology for processing cellulosic feedstocks, i.e., woody biomass, straw, and miscanthus. Regarding residual waste, plasma gasification, being more robust to treat highly heterogeneous material, was selected. The efficiency of the process has been reported to be $52 \%$ [50]. If energy integration is considered, the global efficiency of allothermal gasification can reach 91\% [51] whereas for plasma gasification the efficiency can increase to $62 \%$ [50]. Both technologies were also specified as possible technologies upgrading facilities.

Moreover, four pretreatment technologies are included as part of the BioSNG supply chain design: (1) torrefaction, (2) pelletisation, (3) rotating cone reactor pyrolysis (RCRP), and (4) fluidised bed reactor pyrolysis (FBRP). These pretreatment technologies have been 
extensively investigated for the production of intermediate energy carriers [16] as a way of reducing logistics costs associated with feedstocks transportation. Moreover, the products obtained from these technologies are suitable for a gasification process [52]. ArcGIS 10.2 [53], a Geographic Information System (GIS), was used for preprocessing some of the input data as well as for visualisation purposes. The case study build upon a previous work published by the authors [44], nonetheless, a description is included in the following sections for the sake of completeness.

\subsection{Resources}

The availability of woody biomass resources is estimated based on 4 different sources [54]: (1) forestry residues and stemwood, (2) arboricultural arisings, and (3) sawmill coproducts. Forestry residues have several relevant environmental functions such as source of nutrients, prevention of erosion, habitat provider, etc. This imposes limitations on the usage of forestry residues for renewable energy generation. Accordingly, the European Environmental Agency (EEA) reported a potential availability of $3450 \mathrm{kTon} / \mathrm{yr}$ for 2020 and $2532 \mathrm{kTon} / \mathrm{yr}$ for 2030 [55] after taking into account several environmental factors. Arboricultural arisings are usually chipped and left onsite or used for composting. In 2003, the total availability of arboricultural arisings was reported to be $481 \mathrm{kTon} / \mathrm{yr}$ [56], including total arboricultural contractor arisings and utility work arisings. It is not expected a considerable increase of arboricultural arisings in the future and their availability is estimated to be $68 \%$ of the initial potential if competing markets are taken into account [56]. The availability of arboricultural arisings for energy generation is 332 kTon/yr. The potential of woody biomass for energy generation was estimated to be 3902 $\mathrm{kTon} / \mathrm{yr}$ by 2020. The cost of purchase was set to $65 £ /$ Ton [57]. Regarding sawmill coproducts, $66 \%$ of this resource is in the form of chips (peeled and unpeeled), $20 \%$ is sawdust and $11 \%$ is bark. Only $10 \%$ is potentially available for energy generation due to competing markets [56]. The total production of sawmill coproducts in the UK for 2020 was estimated to be $120 \mathrm{kTon} / \mathrm{yr}$ [58]. Agricultural residues can be used for energy generation applications. Straw from wheat and barley is included as potential feedstock for future projects in BioSNG production. In the UK, straw resources were estimated between 9 and 10 million tonnes per year in 2007. However, a significant fraction is diverted to 
different agricultural activities [59], which reduce the availability to $3000 \mathrm{KTon} / \mathrm{yr}$ [60]. Energy generation from waste streams, e.g. municipal solid waste (MSW), is an interesting application that can have an important role in the waste management strategy of a country while contributing in reducing dependency of fossil fuels. The UK has adopted policies that aim towards a zero waste economy, which gives priority to increase the share of disposal and recycling, whereas limits are imposed not only on the amount of waste for disposal, but also on the percentage that can be treated in waste-to-energy applications [61]. The total residual waste resources were estimated to be around 23,020 kTon/yr in 2020 and decreases to $7544 \mathrm{kTon} / \mathrm{yr}$ by 2040 [62-70]. The resources were calculated as an aggregate of municipal solid waste (MSW), commercial and industrial sector waste streams. The gate fees or residual waste were set to $-€ 35 / T o n$, which is an average of what is reported in literature [71,47]. This value was systematically increased to account for future competition for this resource [47]. Finally, the estimation of miscanthus resources is based on crop productivity [72] and marginal land for energy crops cultivation [73]. In addition, restrictions on marginal land utilisation, based on sustainability and food security aspects, were imposed regionally and nationwide to avoid land competition and over cultivation of miscanthus [74]. The economic aspects related to cultivation of miscanthus were also considered [75]. In order to estimate woody biomass, sawmill coproducts, residual waste and miscanthus resources for each of the UK regions, several maps were used as proxy for this calculation: forestry lands across UK [76], Land Cover Map of Great Britain (LCM2007) [77], and map of active sawmills in the UK [46]. See Appendix C in supporting information. A more detailed description of the availability of woody biomass, cereal straw and residual waste is provided in Appendix D in supporting information.

\subsection{Facilities}

In this work, three types of facilities are considered for two possible paths for production of BioSNG: (1) integrated facilities, (2) upgrading facilities, and (3) pretreatment facilities. In general, integrated facilities consist of a phase of feedstock conditioning, which could include chipping and moisture reduction, gasification, methanation, and gas cleaning. In upgrading facilities the conditioning step is not necessary since the feedstocks have already been preprocessed in pretreatment facilities into higher 
energy density intermediate products. The preprocessing of feedstocks could bring two benefits: (1) installation of smaller upgrading facilities in comparison to integrated facilities, and (2) savings associated with transportation costs. However, this comes at the expense of installing pretreatment facilities. This trade-off will be further discussed in section 5 .

Regarding technologies, gasification is expected to play an important role in the future of sustainable supply chains since it provides an alternative to produce biomass-based platform chemicals. Based on the successful implementation of coal gasification, biomass gasification started being developed in recent years and a number of designs have been proposed [49]. In this work allothermal gasification-based design "MILENA", developed by the Energy research Centre of the Netherlands (ECN), was selected as the main technology for integrated and upgrading facilities processing woody biomass, straw, and miscanthus. Residual waste, however, is highly heterogeneous in its composition which makes this feedstock unsuitable for allothermal gasification. In this case, plasma gasification was selected as this technology is more adequate for handling this type of feedstock [50]. Regarding process efficiencies, it has been reported that gasification of wood chips can achieve an efficiency of $91 \%$ if the process considers energy integration (including methanation and gas cleaning steps) [51].Efficiencies for straw and miscanthus are not reported; therefore they were corrected based on the corresponding low heating values (LHV). The same efficiencies are used for upgrading technologies based on allothermal gasification. Plasma gasification can reach an efficiency of up to $62 \%$ if energy integration is considered [50]. In the case of plasma gasification for upgrading facilities, higher efficiencies have been reported if the residual waste is processed as pellets (or refused derived fuels (RDF)) [78].

Four technologies are investigated for feedstock pretreatment: (1) pelletisation, (2) rotating cone reactor pyrolysis (RCRP), (3) fluidised bed reactor pyrolysis (FBRP), and (4) torrefaction - pelletisation (TOP). It was considered that pelletisation can process woody biomass, straw, residual waste, and miscanthus. Woody biomass, straw, and miscanthus can be used for production of bio-oil through RCRP, bioslurry via FBRP, or torrefied biomass via TOP. Since the production of BioSNG is the main objective, it was assumed that 
the operation of the pretreatment plants is optimised to maximise the output of 411 intermediate products. Accordingly, heat recovery for power cogeneration is only possible 412 for integrated and upgrading plants. Information regarding efficiencies of pretreatment 413 technologies is usually only available for woody biomass. Therefore, the efficiencies for the 414 other feedstocks were estimated by implementing a correction factor based on the 415 corresponding LHVs. This, however, is only an approximation to take into account that 416 different feedstocks have different conversion efficiencies. Accordingly, the efficiency of 417 pelletisation varies from $80 \%$ to $95 \%$ [79,80], being the efficiency of pelletisation of 418 residual waste the lowest. Despite the low efficiency, it is worth mentioning that 419 pelletisation of residual waste presents great benefits in terms of energy density increment which contributes to efficient transportation (lower costs), and smaller upgrading facilities, e.g. the production of $1 \mathrm{MWh}$ of BioSNG requires $770 \mathrm{~kg}$ of residual waste or $330 \mathrm{~kg}$ of pellets. Regarding pyrolysis, the efficiency of conversion for RCRP ranges between 69\% and $74 \%$ whereas efficiencies for FBRP vary from $87 \%$ to $92 \%$ [14]. Finally, TOP has, on average, the highest efficiency, between $94 \%$ and $96 \%$ [14].

Capital investment for a gasification plant based on the MILENA design is reported to 426 be $£ 116$ million for an input capacity of $100 \mathrm{MW}$ for processing woody biomass [19]. A factor of 0.67 is used to take into account economies of scale [47]. As an approximation, the investment costs for straw and miscanthus were estimated through a correction factor based on the corresponding LHVs. The same correction was implemented for upgrading facilities. The capital investment for plasma gasification with an input capacity of $57 \mathrm{MW}$ is estimated in $£ 95 \mathrm{~m}$ [19]. A scale factor of 0.8 was used in this case. The capital investments for pretreatment technologies are considerably low in comparison to integrated facilities. They go from $£ 17$ million for RCRP up to $£ 31$ million for FBRP. The fixed operating costs are on average 3 million per year, for integrated facilities, whereas for pretreatment facilities they range from 1 million per year for TOP and 2 per year million for RCRP. The variable costs were inferred from data available in literature [50,47]. For allothermal gasification, the variable cost of processing woody biomass is $£ 0.0037 \mathrm{~m} / \mathrm{GWh}$, whereas for plasma gasification the variable cost is $£ 0.0236 / G W h$. For pretreatment technologies, the variable costs vary from $£ 0.0014 / G W h$ for pelletisation up to $£ 0.0046 / G W h$ for RCRP. 
440 Table 1 summarises conversion efficiencies for different pretreatment technologies, Capex, 441 and Opex for facilities processing woody biomass with an input capacity of $100 \mathrm{MW}$. For 442 detailed dataset see Appendix E and for sources of data see Appendix F in supporting 443 information.

\section{$444 \quad 4.3 \quad$ Transportation infrastructure}

445 Two types of transportation are considered: local transportation and regional 446 transportation. Local transportation entails procurement of feedstocks and/or delivery of 447 BioSNG to consumers within the same region. Two modes are considered, trucks for 448 feedstocks and intermediate products, and trailers for BioSNG transportation as 449 compressed gas. On the other hand, regional transportation refers to transfers of feedstock 450 and/or BioSNG between regions. Besides trailers and trucks, rail is also included as an 451 additional transportation mode for feedstocks and intermediate products. Local and 452 regional transportation distances were calculated based on road network and rail network 453 maps [81] (see Appendix G in supporting information). Fixed and variable transportation 454 costs are summarised in Table 2.

\section{$455 \quad 4.4$ Demand}

456 The gas and power demand were set up according to projections of the GoneGreen 457 scenario reported in The Gas Ten Year Statement (GTYS) published by the UK National Grid 458 [82]. The heat recovered from energy integration in integrated and upgrading facilities can 459 be converted into power assuming a cogeneration efficiency of 40\%. Projections for gas 460 and power prices were fixed based on UK Future Energy Scenarios published by the 461 National Grid [83]. The future gas and power demand as well as their corresponding 462 forecasted prices are shown in Figure 2. 


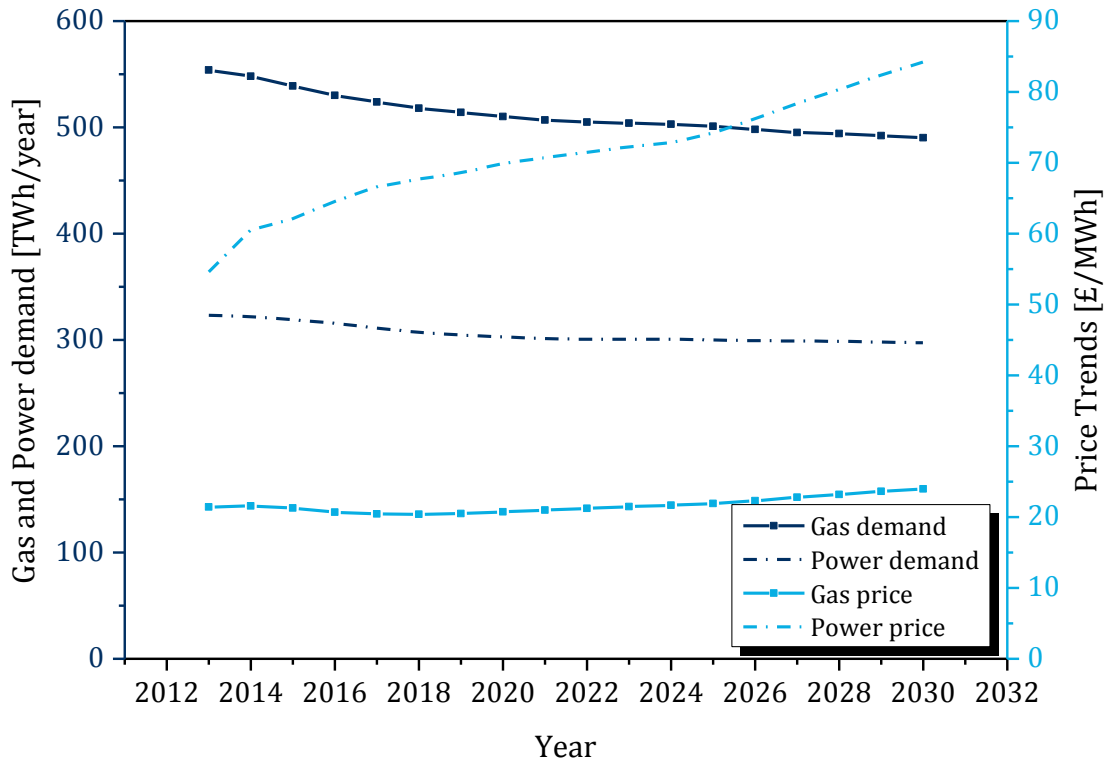

Figure 2. Forecasted gas demand for GoneGreen scenario [82,83] (reproduced from ref [44])

The BioSNG is transported to offtake points that connect the gas transmission system to the gas distribution network. The BioSNG is then supply to final customers through local distribution zones (LDZ). There are in total 13 LDZs that supply 65\% of the total gas demand in the UK. Finally, it was assumed that the electricity generated is sold locally. See Appendix $\mathrm{H}$ in supporting information for a detailed description of the gas transmission system.

\section{Results and discussion}

In this section we present computational results for the case study described previously in section 4. The production of BioSNG and cogeneration of power generation along with their corresponding incentives, feed-in tariff for BioSNG and ROCs for power generation, are included for all the cases discussed in this section. First, the relevance of pretreatment technologies in the design of BioSNG supply chains is addressed and their benefits are identified by comparing with a scenario in which only integrated technologies are considered. Second, the role of the government in developing these technologies is investigated through feed-in tariffs. For this purpose, a parametric analysis was carried out in which different levels of subsidisation are explored and their impact on feedstock procurement, installation of facilities and production of BioSNG is discussed. In addition, 
the repercussion of uncertainty associated with 6 parameters: capital costs, feedstock cost, technology efficiency, feed-in tariff, gas and power prices, is studied through global GSA. GSA allows to simultaneously address uncertainty in the input data described by means of a probability distribution function (PDF) and prioritised those parameters with major impact on the global performance of the supply chain. Finally, an analysis is presented in which we address scenarios that allow to detach the development of BioSNG from government subsidies.

The optimisation problems were solved using GAMS 24.7.1. The MILP problem was solved with CPLEX 12.6.3. All runs were performed on a Dell OptiPlex 9010 with Intel® Core $^{\mathrm{TM}}$ i7-3770 CPU @3.40 GHz and 16 GB RAM running Windows 7® Enterprise (64-bit operating system). The optimality gap was set to less or equal to $1 \%$ for all cases. The corresponding statistics are presented in Table 3.

\subsection{Impact of pretreatment technologies}

In this section we present the results for a case study in which two different paths are considered for production of BioSNG and power cogeneration. The first path, which has been addressed in a previous work by the authors [44], can be regarded as a centralised route since it consists merely of integrated facilities in which raw feedstocks are directly processed into BioSNG. The second path, which can be seen as a distributed route, considers installation and operation of pretreatment plants for processing raw feedstocks into intermediate products of higher energy density. The intermediate products are then transported to upgrading plants where gasification and methanation processes take place to produce BioSNG along with power cogeneration. Regarding government subsidisation, $\mathrm{a}$ feed-in tariff was set to $£ 70 / \mathrm{MWh}$ for injection of BioSNG into the national gas pipeline transmission system. For power generation, ROCs were set to 1.8 per MWh at a price of $£ 45 /$ ROC $[84,85]$.

The economic performance of the case study is summarised in Figure 3. In general, the total costs associated with the development of the BioSNG supply chain are mostly dominated by operational costs (51.2\%), with the rest equally distributed between capital investments (24.2\%) and taxes (24.6\%) (see Figure 3a). The results show that tax 
511 payments are an important component of the total cost. Consequently, this could be used as

512 an additional mechanism for the government to stimulate the development of BioSNG as a 513 sustainable primary energy source.

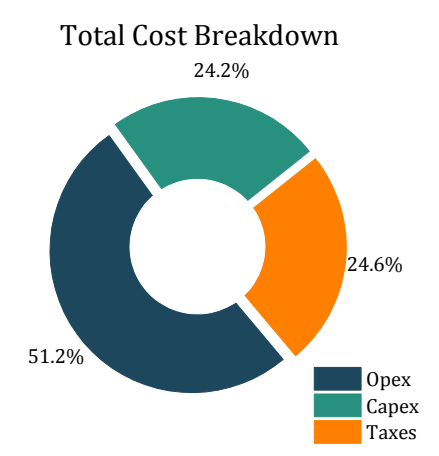

a

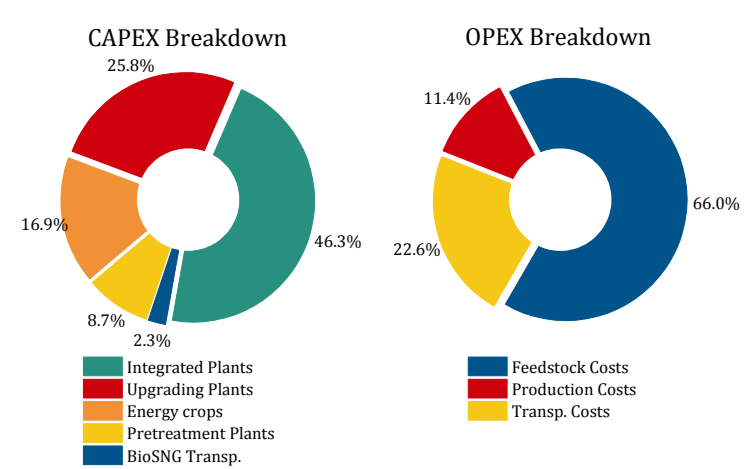

b

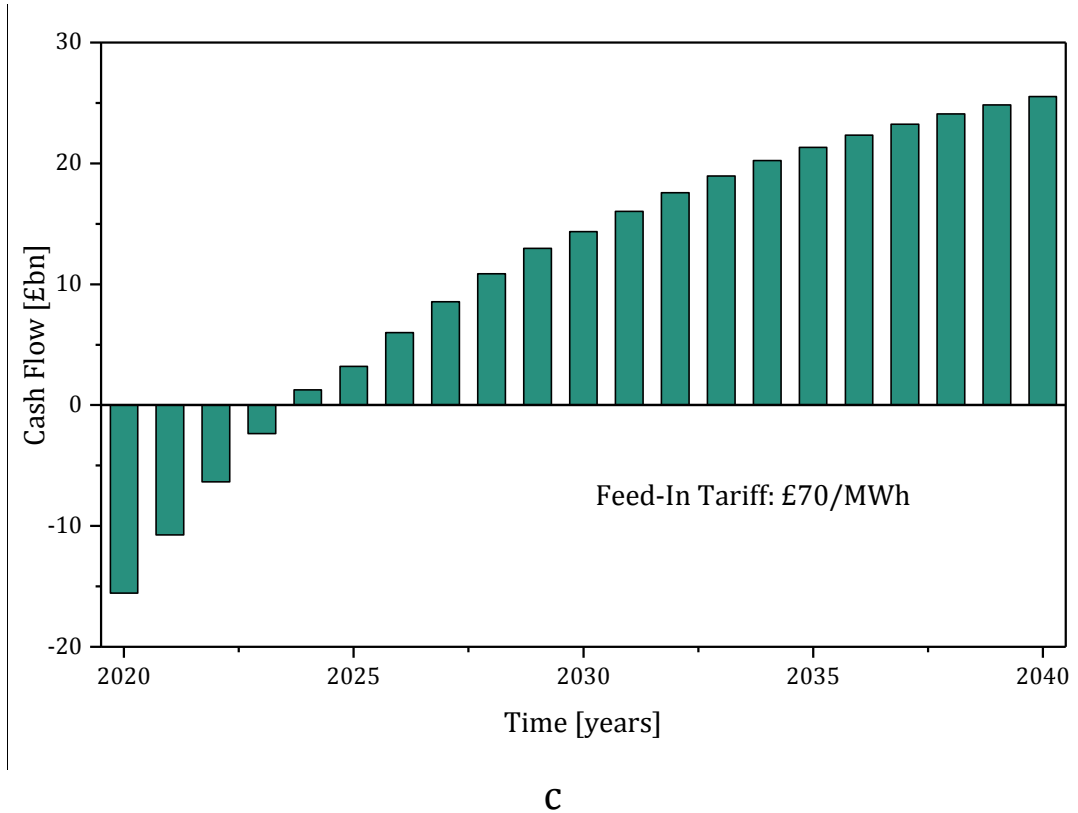

514

Figure 3. Summary of the economic performance: (a) total cost breakdown. (b). Capex and Opex Breakdown.

(c) Cumulative net cash flow

The capital expenditures are largely defined by the development of infrastructure for BioSNG production rather than for transportation. $46.3 \%$ of the investments are destined to develop the first path, whereas the development of the second path, in which pretreatment and gasification-methanation processes are decoupled, accounted for 34.5\% of the total investments. Energy crops, in this case miscanthus, required $16.9 \%$ of the total capital cost whereas investment in infrastructure for local and regional transportation of BioSNG by road is only $2.3 \%$. Concerning operational expenditures, $66 \%$ corresponds to 
523 feedstock purchases and $22.6 \%$ was required for transportation of feedstocks and 524 intermediate products. This means that $33.8 \%$ of the total cost is due to feedstock 525 purchases, whereas $19.5 \%$ are associated with facilities investment. Moreover, the 526 transportation component is almost double of what is spent on the actual operation of the 527 production facilities. These figures highlight the considerable impact of feedstock 528 acquisition and transportation on the economy of these types of supply chains. Finally, the 529 cumulative discounted cash flow (Figure 3c) shows that the production of BioSNG is 530 profitable with a net present value of $£ 25.5$ billion after 20 years and a breakeven time of 5 531 years.

532 On average, $21.2 \%$ of the total gas demand was supplied by the production of BioSNG 533 and $4.3 \%$ of the power demand was supplied by cogeneration. Miscanthus plays a crucial 534 role in these figures since $65.1 \%$ of the total BioSNG production comes from this energy 535 crop. Residual waste comes in second place with enough resources to provide $17.5 \%$ of the 536 BioSNG production. Woody biomass and straw only contributes with $9.4 \%$ and $7.9 \%$, 537 respectively. The design of the BioSNG supply chain for each feedstock is shown in Figure 4 538 and Figure 5. 


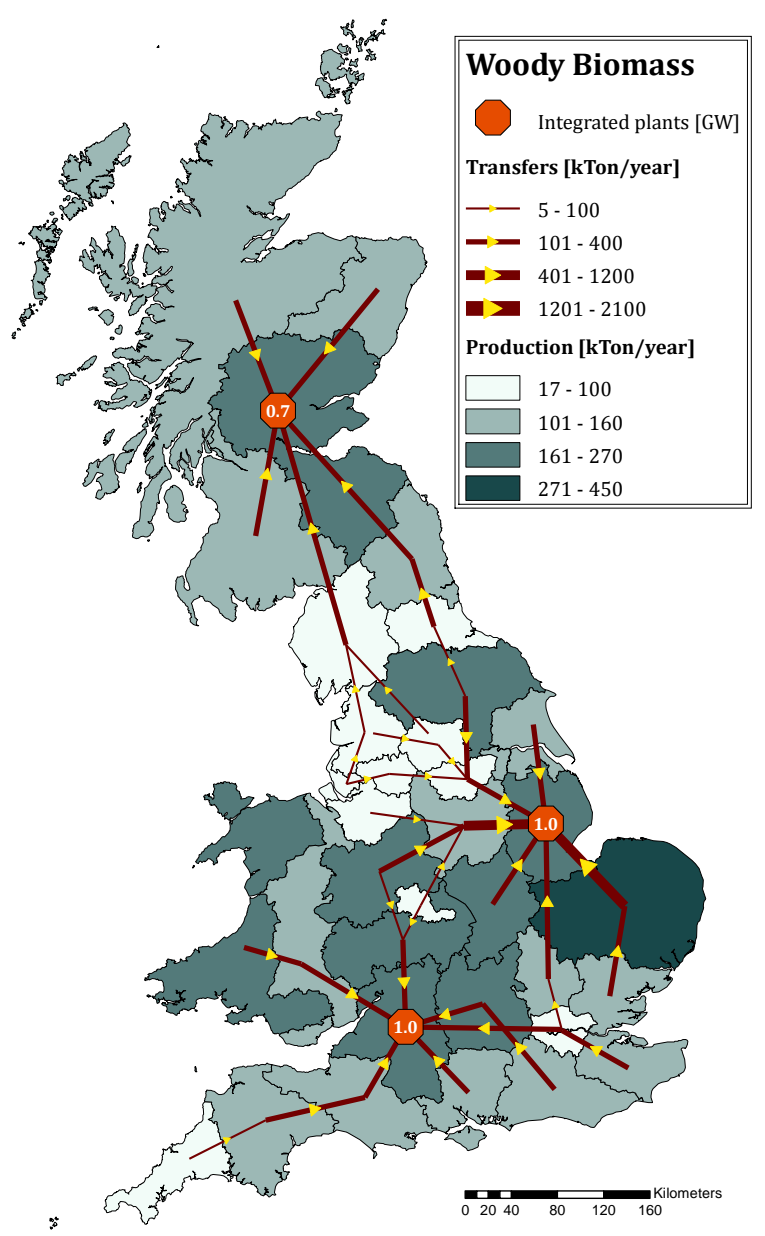

a

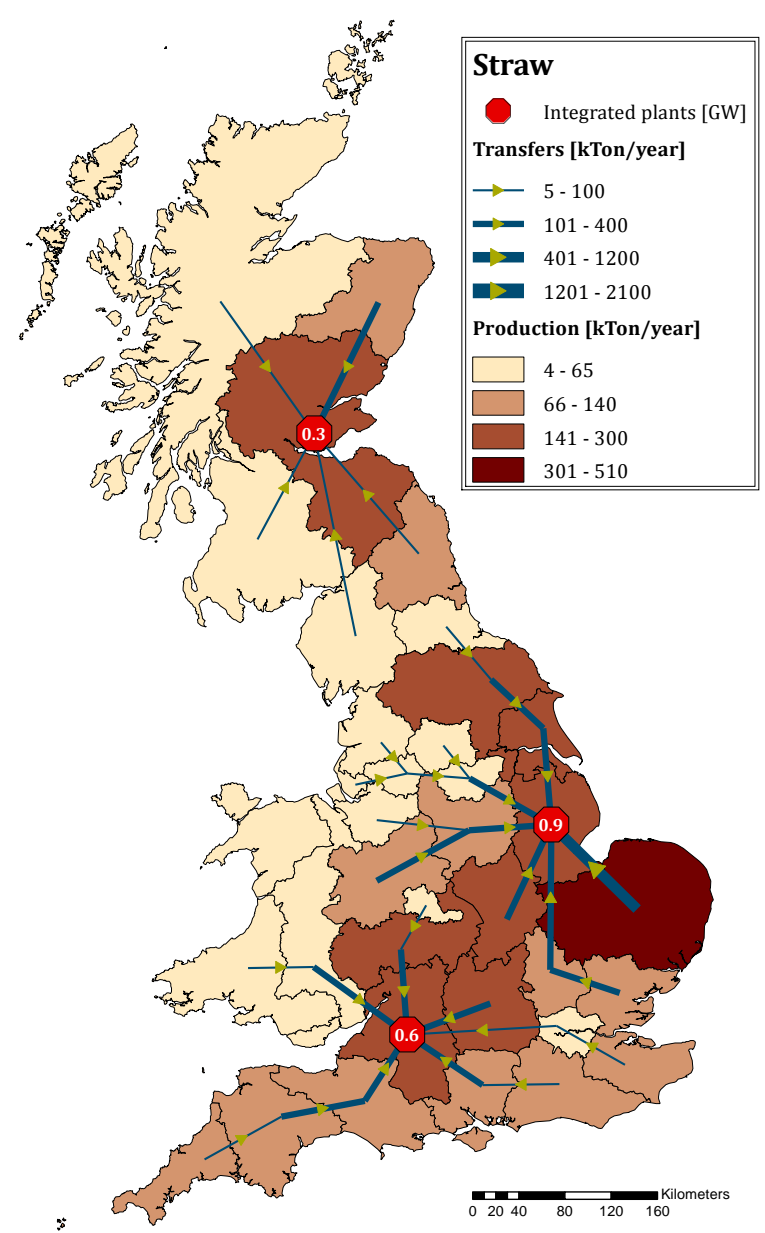

b

Figure 4. Design of the BioSNG supply chain for different feedstocks: (a) Woody biomass. (b) Straw.

The supply chains for producing BioSNG from woody biomass and straw were designed following a centralised scheme in which only integrated technologies intervene. The total installed capacity was $2.7 \mathrm{GW}$ for woody biomass and $1.8 \mathrm{GW}$ for straw. The location of facilities in the south, central area and north of the UK aims to minimise the transportation costs of the raw materials, considering that they are fairly distributed across the regions. England produced $80 \%$ and $85 \%$ of woody biomass and straw, respectively. The processing of woody biomass and straw takes place mostly in England where 79\% of woody biomass and $85 \%$ of straw is converted into BioSNG. The remaining 11\% of woody biomass and 15\% of straw is processed in Scotland. Both resources are being utilised at their maximum availability. The fact that no pretreatment technologies were chosen can be explained by the low contribution of these resources in the production of BioSNG due to low availability. Consequently, the volume of these resources is not enough to compensate 
552 for investment in pretreatment facilities in order to reduce costs on transportation.

553 Regarding the transportation modes, $90 \%$ of the woody biomass is transported via rail and 554 only $10 \%$ by truck. In the case of straw, truck is the preferred mode with $65 \%$ of the straw 555 delivered by this mode, whereas the remaining 35\% was delivered by rail. waste involves torrefaction and pelletisation, respectively (Figure 5).

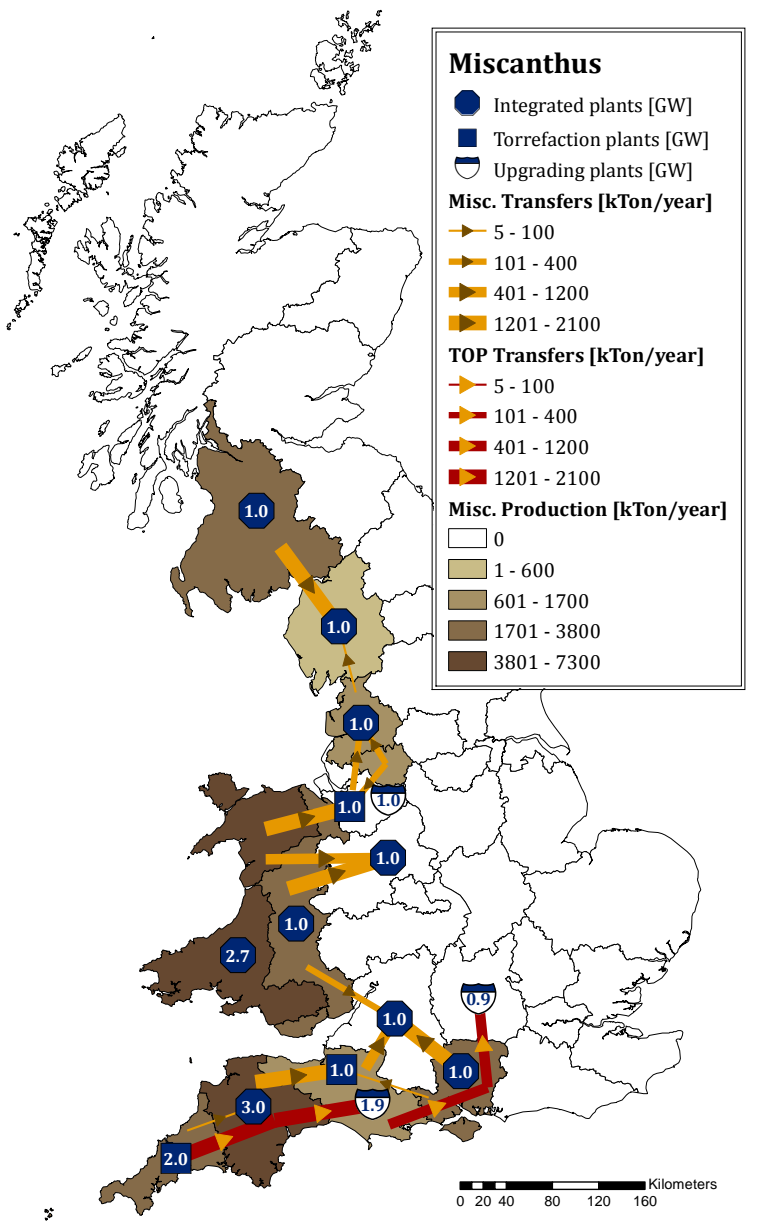

a

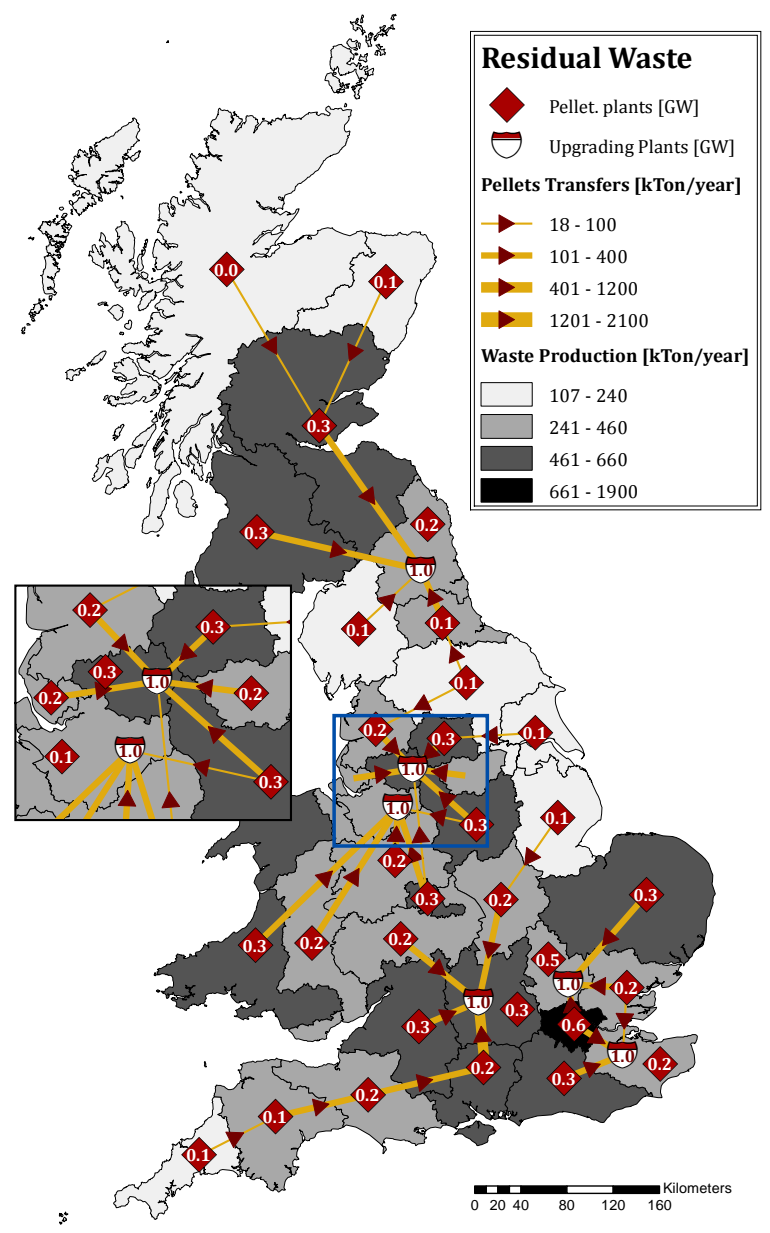

$\mathrm{b}$

Figure 5. Design of the BioSNG supply chain for different feedstocks: (a) Miscanthus. (b) Residual waste.

In the case of miscanthus, the cultivation of this energy crop is primarily developed along the west part of the UK. These regions have in common favourable conditions for energy crops cultivation that lead to high productivity in terms of tonnes per hectare.

562 England contributes with 54\% of the total production of miscanthus, followed by Wales $563(34 \%)$ and finally Scotland (12\%). The total installed capacity for processing miscanthus in 
integrated plants is $12.7 \mathrm{GW}$. An alternative path was selected to produce BioSNG from miscanthus in which torrefaction-pelletisation was chosen as pretreatment technology with a final capacity of $4 \mathrm{GW}$, followed by further processing in upgrading plants, whose final capacity is $3.8 \mathrm{GW}$. This path is mostly developed in the south region of the UK, where the production of miscanthus is comparatively higher than in the other regions. Moreover, $67 \%$ of miscanthus was processed through integrated facilities, whereas the other $33 \%$ was processed through pretreatment and upgrading facilities. Regarding the transportation modes, $60 \%$ of raw miscanthus was delivered by rail, and the rest was delivered by truck. Torrefied miscanthus, on the other hand, was transported exclusively by rail. Regarding residual waste, its procurement is primarily focused in England which supplies 83\% of the total residual waste resources. Scotland and Wales contribute with $10 \%$ and $7 \%$, respectively. The supply chain design features a distributed scheme in which pretreatment facilities were installed in each of the 35 regions to process $100 \%$ of the resources into pellets (or RDF). Only $2 \%$ of the residual waste was transported to a different region without previous pretreatment (not shown in the map for the sake of simplicity). The residual waste pellets are processed in upgrading facilities distributed in five regions across England. This arrangement allows to reduce considerably not only transportationrelated costs but also the size of facilities required for final conversion into BioSNG, which is reflected on the capital investments. The total installed capacity was $7.5 \mathrm{GW}$ for pelletisation plants and $6 \mathrm{GW}$ for upgrading plants. Despite the high generation of residual waste in London, none of the upgrading plants are located in this city. Instead, the facilities were installed in surrounding regions, acting as "hubs" for the residual waste pellets produced in the east part, including London. The preferred mode for transportation of residual waste pellets is rail, which delivered $95 \%$ of the total production. The marked preference for pelletisation of residual waste as a first step stems mainly from a considerable potential for volume reduction, and therefore increase in energy density, which has positive effects on the transportation infrastructure and processing facilities.

In summary, in terms of energy units, England leads the production of feedstocks with $65 \%$ of the total production in 20 years, being miscanthus the main feedstock. Wales contributes with $23 \%$ driven mostly by the production of miscanthus, and Scotland comes 
594 in third place with $12 \%$ of the total feedstock production, also with miscanthus as main 595 feedstock. Rail is a crucial transportation mode since it delivered $79 \%$ of the combined 596 production of raw feedstocks and intermediate products. The remaining $21 \%$ was 597 transported via trucks. Regarding processing infrastructure, 53\% of the total installed 598 capacity, including integrated, pretreatment, and upgrading facilities, was built for 599 processing miscanthus. Similarly, the infrastructure for processing residual waste equals $60035 \%$ of the total capacity, whereas forestry and straw required only $7 \%$ and $5 \%$, 601 respectively. In terms of geographic distribution, the infrastructure for BioSNG production 602 is largely located in England (82\% of the total installed capacity), followed by Wales (11\%), 603 and Scotland (7\%). Accordingly, England is the major BioSNG supplier with 79\% of the 604 total production. Moreover, the transportation of BioSNG takes place only locally between 605 the facilities and the injection points located in the same region.

606 607 608 609 610 611

The benefits of including pretreatment technologies are identified by comparing with a scenario in which only integrated technologies are considered. A summary for both cases is presented in Table 4.

If only integrated technologies are considered, the NPV drops to $£ 21.4$ billion, which corresponds to a reduction of $16 \%$ in profitability. This is mainly caused by an increment in infrastructure investment (16.9\%) and operational costs (11.6\%). Specifically, investment in integrated plants is $21 \%$ higher than the total investment in facilities for the scenario in which pretreatment technologies are also an alternate option. This is mainly a result of pelletisation of residual waste, which allows installation of less expensive facilities for producing BioSNG. Namely, when pretreatment technologies are included, the optimisation framework selects a total capacity of 7500 MW for pelletisation, and 6000 MW for upgrading pretreated waste. The combined investment does not surpass the investment for installing $7500 \mathrm{MW}$ to process directly residual waste. The key is the extremely low energy density of residual waste in comparison to waste pellets. Therefore, a higher capacity in terms of tons/year is required in order to reach the same output in MW. Correspondingly, the operational costs increased $11.6 \%$ due to a drastic increase in production costs of $81 \%$, which is a result of installing larger facilities. In addition, the transportation costs increased $14 \%$ when no pretreatment technologies are included. Notably, the income component 
624 from BioSNG and Power sales increased 1.7\%. Similarly, incentives from feed-in tariff and 625 ROCs increased $1.4 \%$. This is related to the fact that a supply chain based merely on 626 integrated technologies is more efficient in terms of utilisation of feedstocks which reflects 627 on a higher production of BioSNG in 1\%. By contrast, when pretreatment technologies are 628 added to the supply chain, the global energy losses are higher and therefore the net 629 production of BioSNG decreases. In addition, the power sales increase by $2.9 \%$ due to 630 intensification of cogeneration which is related to installation of more integrated 631 technologies. This is also reflected in income through the subsidisation schemes. Woody

632 biomass and straw are used at their maximum availability; nonetheless their contribution 633 to the production of BioSNG is overshadowed by miscanthus which continues to be the 634 dominant feedstock. The results show that the integration of pretreatment technologies in 635 the design of BioSNG supply chains benefits the global economic performance.

\section{$636 \quad 5.2$ The role of feed-in tariffs}

637 In this section, we investigate the impact of different subsidisation schemes on the 638 general performance of the BioSNG supply chain. In this case, a parametric analysis was 639 implemented in which the feed-in tariff was systematically increased from $£ 0 / \mathrm{MWh}$ up to $640 £ 100 / M W h$. In reality, based on the current policies established by the UK government, it is 641 unlikely that the subsidisation for gasification through feed-in tariffs will reach $£ 100 / \mathrm{MWh}$. 642 Nonetheless, these levels of subsidisation are included in the analysis for the sake of 643 completeness. The corresponding results are summarised in Figure 6. 


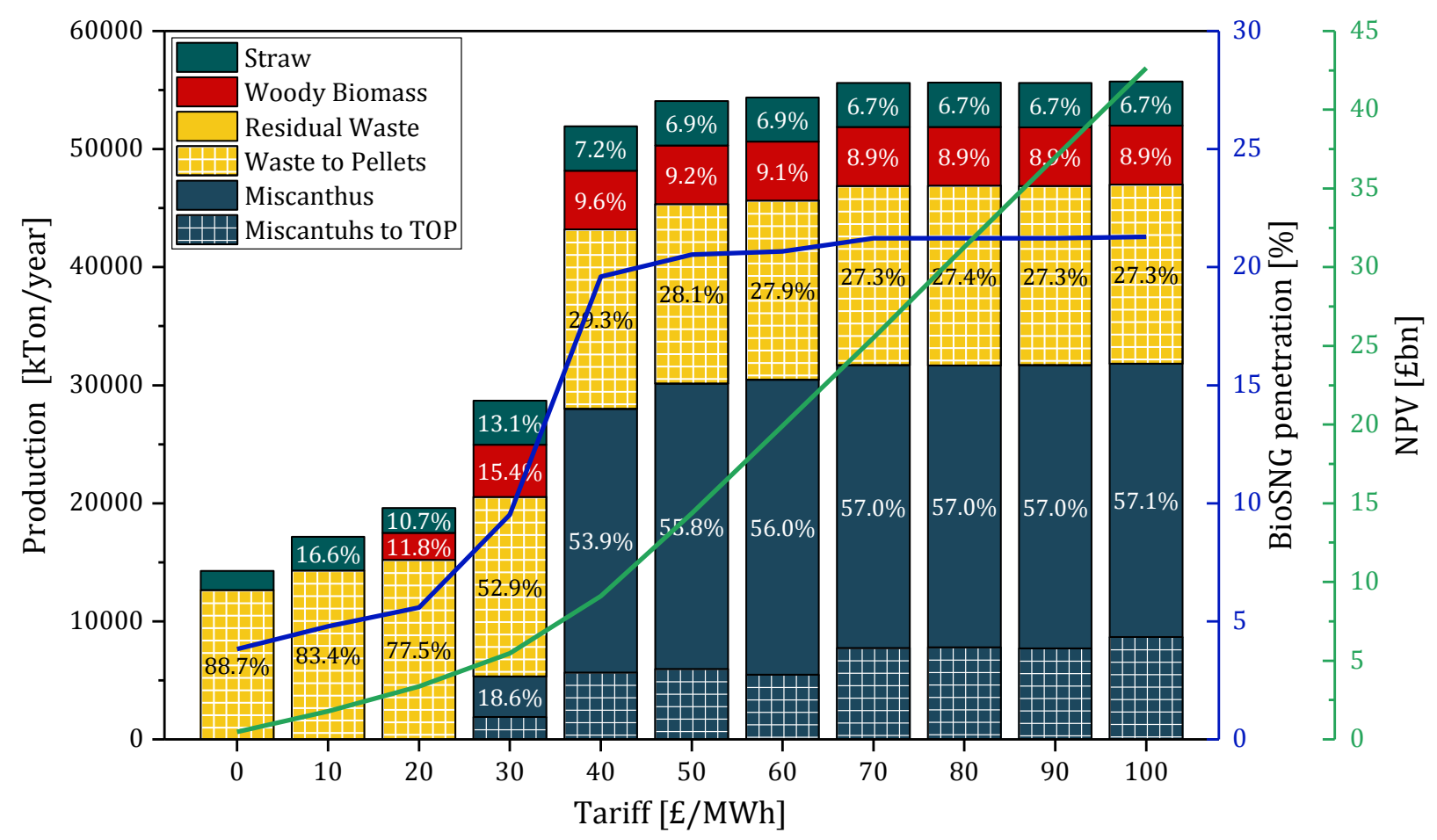

644

646

647

648

649

650

651

652

653

654

655

656

657

658

659

660

661

Figure 6. Impact of government policies on the development of BioSNG supply chains.

The production of BioSNG is economically feasible even when the feed-in tariff is set to $£ 0 / M W h$. However, the NPV is only $£ 0.5$ billion and the BioSNG penetration is $3.8 \%$. The production of BioSNG is based largely on residual waste and a small fraction of straw. The utilisation of both feedstocks is $83 \%$ and $43 \%$ for residual waste and straw, respectively.

The white grid represents how much of the feedstock was sent to pretreatment facilities. In this case, $100 \%$ of the residual waste was sent to pelletisation. It is worth to mention that in absence of subsidisation, a BioSNG supply chain based exclusively on integrated plants is not economically feasible. When the tariff is set to $£ 10 / \mathrm{MWh}$, the procurement of residual waste and straw increases reaching a utilisation of $94 \%$ and $76 \%$, respectively. The NPV increased almost four times to $£ 1.8$ billion and the supply reached $4.8 \%$. At $£ 20 / \mathrm{MWh}$, residual waste is used at its maximum availability, and woody biomass is included as an additional feedstock for production of BioSNG. At this level, only pelletisation is being used. The NPV is $£ 3.4$ billion and the BioSNG penetration is $5.6 \%$. Comparatively, when only integrated technologies are considered, the minimum tariff required for a feasible development is $£ 20 / \mathrm{MWh}$, in which the NPV is $£ 0.2$ billion and only a supply of $2.6 \%$ is reached. The cultivation of miscanthus starts only after the tariff is set to $£ 30 / \mathrm{MWh}$, part of 
the production of miscanthus is pretreated with torrefaction (white grid). Residual waste and straw are being used at their maximum availability, and woody biomass utilisation is 88\%. The NPV increased $62 \%$ from the previous case reaching $£ 5.5$ billion. The BioSNG supply is $9.5 \%$ of the total demand. A tariff of $£ 40 / \mathrm{MWh}$ increases drastically the BioSNG supply up to $19.6 \%$. This is particularly driven by a boost in miscanthus cultivation. At this point miscanthus becomes a dominant feedstock. The economy performance largely benefits from this, reaching an NPV of $£ 9.1$ billion. Further increments in the level of subsidisation are reflected on the NPV but do not have major impact on the cultivation of miscanthus and therefore the percentage of demand met by BioSNG. Finally, at $£ 100 / M W h$, it was possible to reach $21.3 \%$ of penetration of BioSNG with a corresponding NPV of $£ 42.6$ billion. The production of BioSNG across the UK with variation of feed-in tariffs is summarised in Figure 7.
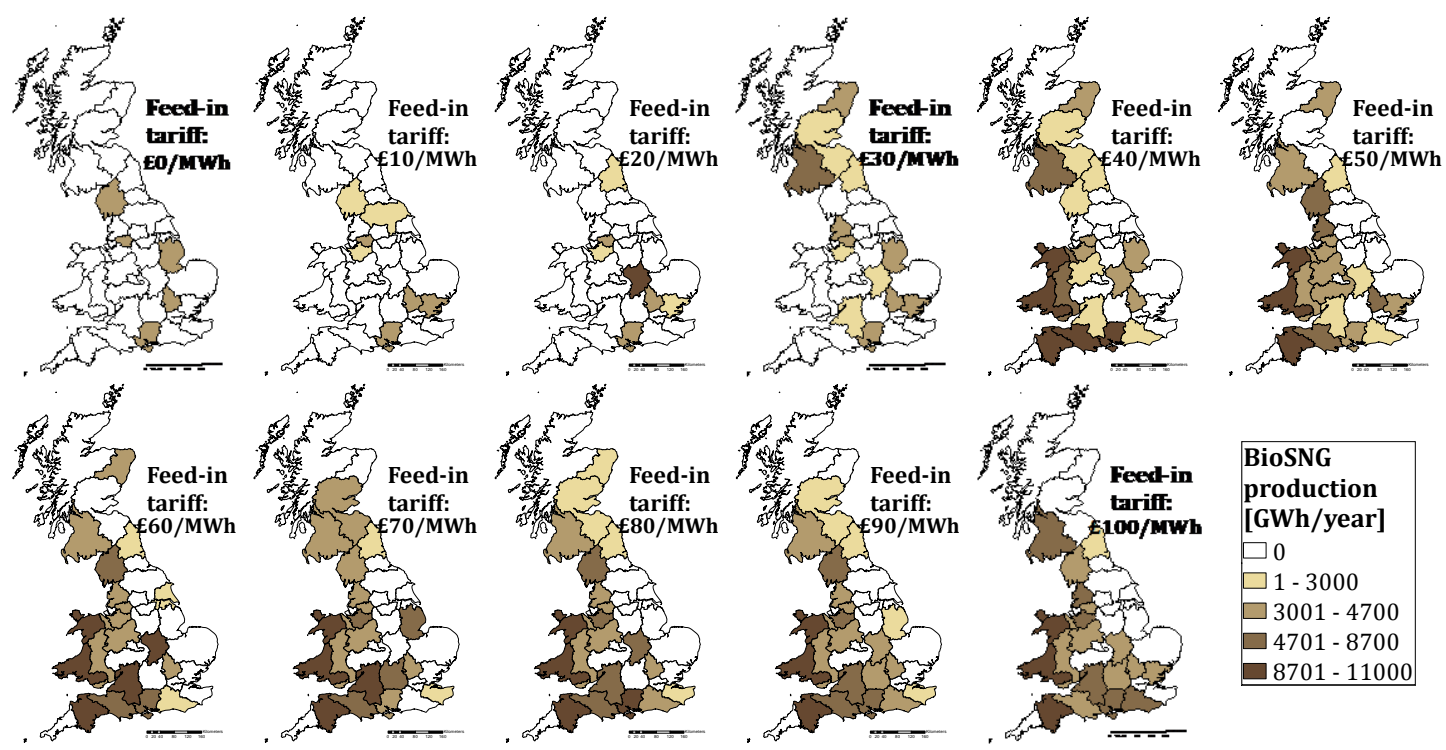

Figure 7. Geographic distribution of production of BioSNG with different levels of subsidisation.

Initially the production of BioSNG is scattered across England, as the tariff increases up to $£ 20$ /MWh the production intensifies but continues to be centred in England. At a tariff of $£ 30 / M W h$, the production of BioSNG initiates in three regions of Scotland. At this point all the resources of residual waste and straw, and most of the woody biomass are being transported to these regions. Once the tariff reaches the critical point of $£ 40 / \mathrm{MWh}$, Wales starts producing BioSNG. This production depends almost exclusively from cultivation of miscanthus. Similarly, more facilities are installed in the south of England whose 
production of BioSNG is based mainly on miscanthus. Therefore, the drastic increase in BioSNG supply discussed previously can be traced to Wales and three regions in the south of England. As the subsidisation increases the production in Scotland alternates between 2 and 3 regions. Similarly, the production of BioSNG in the east and central part of England presents variability in the location of facilities. By contrast, the regions whose BioSNG production relies mostly on local resources of miscanthus are consistently selected as the feed-in tariff increases.

\subsection{Key parameters in BioSNG supply chains - A global sensitivity analysis (GSA) approach}

The results presented in previous sections showed favourable economic metrics for the introduction of BioSNG in the energy mix of the UK. Nonetheless, the information that serves as the basis for this type of analysis is usually subject to substantial uncertainty that undoubtedly affects the economic performance of a supply chain. Therefore, it is essential to quantify the consequences of uncertainty and identify those parameters that can potentially have a major impact on the economics of a BioSNG supply chain. In this study we investigate the effects of uncertainty in six parameters on the design of the BioSNG supply chain via GSA [86-88]. The parameters selected for the analysis are: technology efficiency, feedstock cost, capital cost of facilities, feed-in tariff, and gas and power spot prices. The data regarding the uncertainty for gas and power prices was based on three scenarios (low, medium, high) published by National Grid UK [89]. Additionally, a $\pm 10 \%$ of variation was considered for technology efficiency, whereas capital costs and feedstock costs were assumed to vary $\pm 30 \%$ from the base case. In the case of feed-in tariff, based on the analysis discussed in section 5.2, the subsidisation level was allowed to range between $£ 0 / \mathrm{MWh}$ and $£ 50 / \mathrm{MWh}$. Initially, the implementation of the GSA requires setting probability distribution functions for each uncertain parameter. In this work, we assumed beta distribution function for gas and power prices. In the case of technology efficiency a normal distribution was chosen so that approximately $95 \%$ of the data falls within $\pm 10 \%$ of variability. Finally, a uniform distribution was chosen for Capex, feedstock costs, and feedin tariff. A Quasi Monte Carlo method based on Sobol sequences [90] was implemented along with a Random Sampling-High dimensional model representation (RS-HDMR) method [90-92] was used which allows to approximate the input-output behaviour of high 
713 dimensional systems with minimum sampling effort. Therefore, despite the complexity of 714 the optimisation model, this methodology allows to estimate sensitivity indices based on 715 few samples. In this work, 128 scenarios were generated from sampling the uncertain 716 parameters in order to calculate first order effects and total effects. First order effects 717 determine the impact of changes in one parameter on the variance of the output variables 718 without considering interactions with other parameters. Total effects account for the 719 variance of the output variables due to the combined contribution of changes in the 720 uncertain parameter as well as its interaction with the other parameters. The GSA was 721 implemented with the software SobolGSA [93]. The corresponding results are summarised 722 in Figure 8.

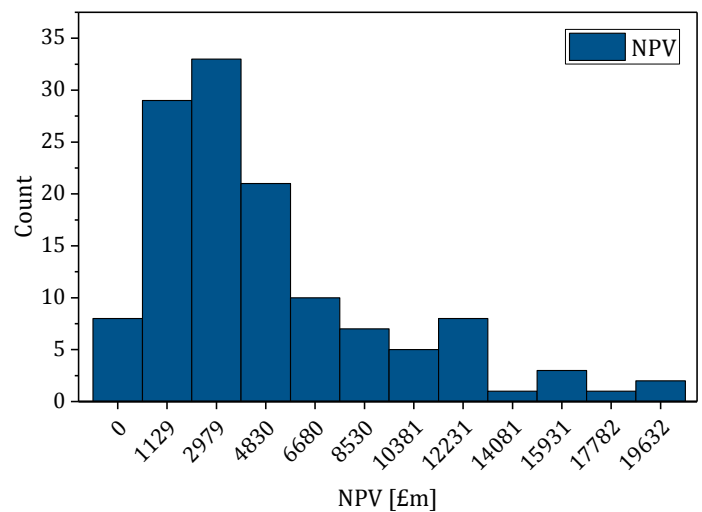

a

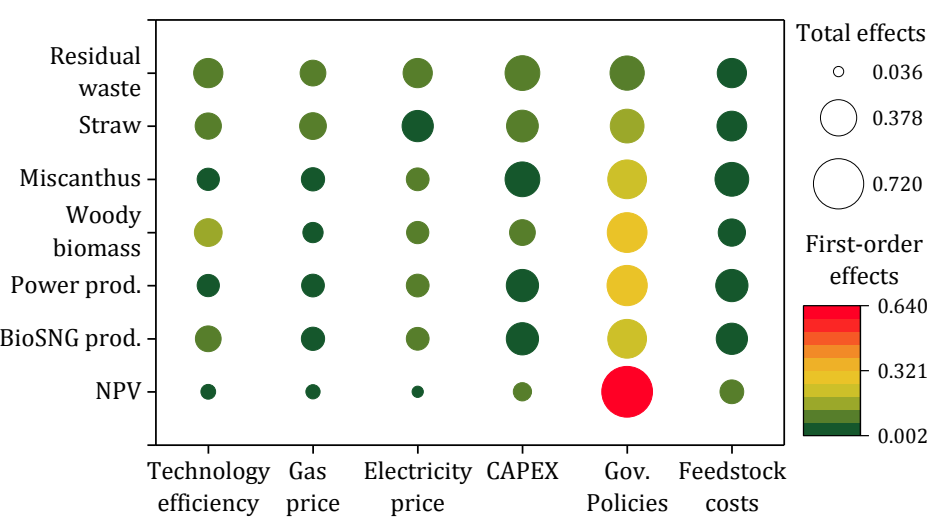

b
723 724

725

726

727

728

729

730

731

732

733

734

Figure 8. Global sensitivity analysis for the BioSNG supply chain: (a) Distribution of NPV. (b) First order and total effects

The distribution of the NPV for 128 scenarios is presented in Figure 8a. The NPV presents high variability, with some scenarios not economically feasible, and a few scenarios with an NPV of around $£ 19.6$ billion. The median is $£ 3.7$ billion which is considerably lower than the values reported in previous sections. Likewise, the BioSNG supply ranges from $0 \%$ up to $25 \%$, with median of $9 \%$. It is important to clarify that the distribution presented in Figure $8 \mathrm{a}$ is derived from the optimisation of each scenario individually, and it is not a result of the implementation of a method for stochastic optimisation.

Figure $8 \mathrm{~b}$ presents a summary of the first order effects, represented by a colour scale, and the total effects, represented by the size of the bubbles. The results indicate that 
government policies i.e. subsidisation level, is the component with the largest impact on the economic performance of the BioSNG supply chain. $63.7 \%$ of the variance of the NPV is related to individual effect of subsidisation policies. Feedstock costs come in second place whose associated uncertainty accounted for $9.7 \%$ of the variance in NPV. Similarly, the interaction of government policies and feedstock costs with other parameters accounted for $71.8 \%$ and $15.9 \%$ of the variance of NPV, respectively. Moreover, the subsidisation 741 policies have a dominant impact on the utilisation of woody biomass and miscanthus. The 742 latter relates to the predominant influence of subsidisation on the production of BioSNG 743 and power whose corresponding first order effects are $24.1 \%$ and $27.8 \%$, respectively. The 744 independent effects of capital costs of facilities, feedstock costs, electricity price, gas price 745 and technology efficiency are in general low for the rest of the output variables $(6 \%$ on 746 average), with exception of technology efficiency on woody biomass utilisation with a 747 corresponding first order effects of 14.7\%. Moreover, when the interactions of capital costs 748 and feedstock costs with all the parameters are considered, they have a comparable effect 749 to subsidisation policies on the miscanthus utilisation, which also reflects on the BioSNG 750 production and power cogeneration. Notably, the first order effects and total effects of 751 subsidisation policies on residual waste and straw utilisation are comparable to the rest of 752 the uncertain parameters. This indicates that, in comparison to the other feedstocks, the 753 development of BioSNG supply chains based on residual waste and straw is not strongly 754 dependant on subsidisation tariffs. This had been previously hinted by the results 755 presented in Figure 6. In fact, both feedstocks are consistently selected for production of 756 BioSNG in most of the 128 scenarios as shown in Figure 9. 


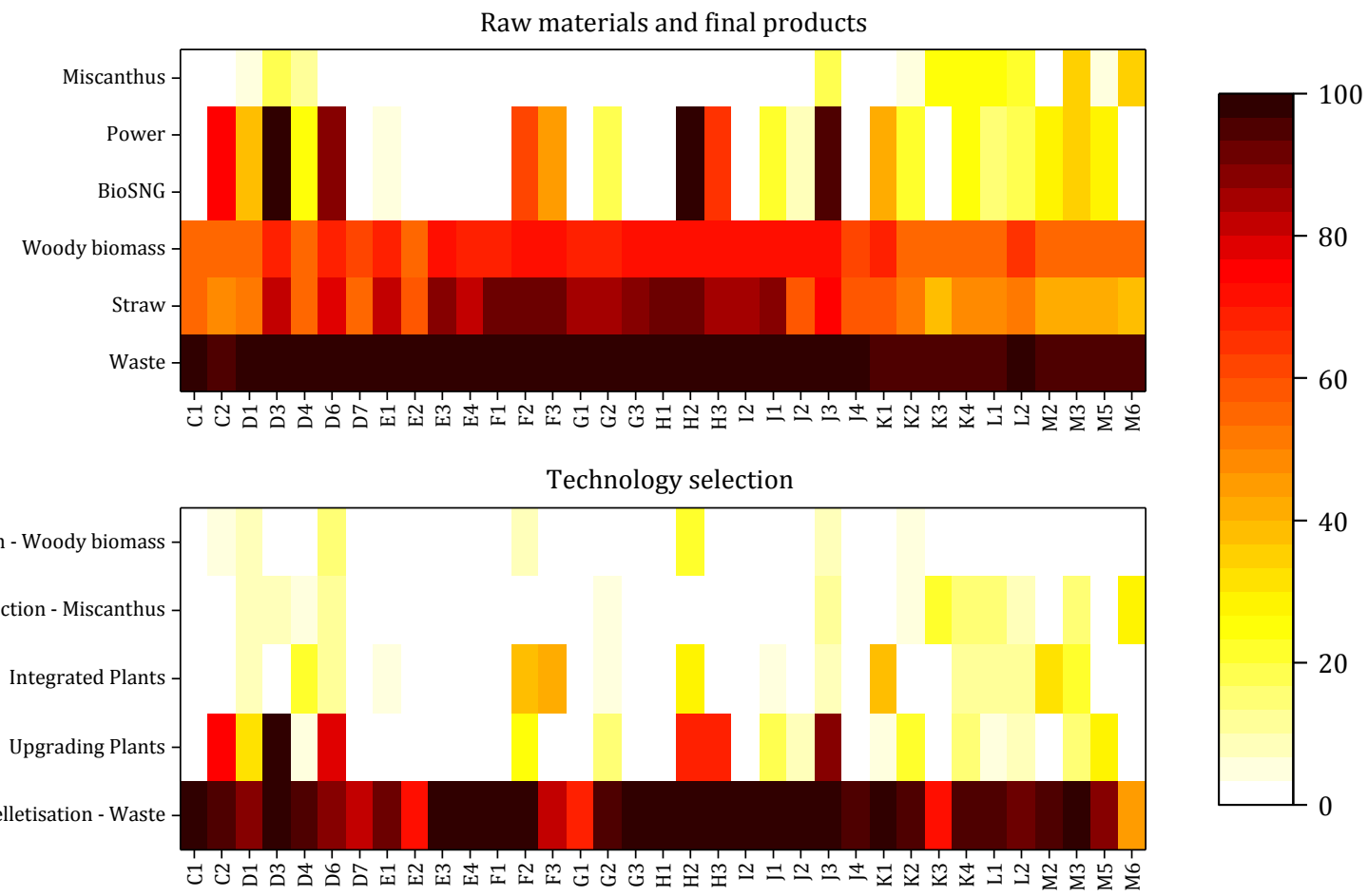

757

758

759

760

761

762

763

764

765

766

767

768

769

770

771

772

773

Figure 9. Heat maps for feedstocks and technology selection based on GSA

Figure 9 summarises the percentage of number of times (with respect to 128 scenarios) that raw materials, final products, and processing technologies are active in each one of the regions of the UK. Regarding raw materials and final products, it is clear that despite the variability of the uncertain parameters, the utilisation of residual waste across the UK is considerably high (above 94\%), which makes it the preferred feedstock for production of BioSNG. The utilisation rate of straw is relatively high in England with certain preference towards East Midlands (F1-F3), West Midlands (G1-G3), and East of England (H1-H3) where straw was used in 90\% of the scenarios. In Scotland (M2-M3, M5-M6), straw was produced in around $40 \%$ of the scenarios. The utilisation rate of Woody biomass is more homogenous across the UK, ranging between 54\%, in Scotland and north of England (C1, C2, and D1), and 70\% in England (E3-J3). The results for miscanthus show that the cultivation of this energy crop is mostly concentrated on Wales (L1-L2), five regions in England (D3, D4, J3, K3, and K4), and two regions in Scotland (M3 and M6). However, the selection rate of miscanthus is $17 \%$ which is very low in comparison to the other three feedstocks. Despite being crucial to achieve high BioSNG supply, the production 
774 of miscanthus is vulnerable to unfavourable government policies, which can hinder its 775 development across the UK. Four regions in England (D3, D6, H2, and J3) are selected in $77694 \%$ of the scenarios to install facilities for BioSNG production and power cogeneration.

777 From the figure it seems that upgrading plants are the preferred choice in these regions,

778

779

780

781

782

783

784

785

786

787

788

789

790

791

792

793

794

795

796

797

798

799

800

801

802

which reaffirm the importance of a distributed route for BioSNG production. The selection of integrated facilities is low in comparison to the upgrading facilities. This can be explained by the fact that most of the installation of integrated facilities is linked to the cultivation of miscanthus; since this feedstock is severely affected by the variability in the subsidisation tariffs, this is reflected on the infrastructure development. Among the pretreatment technologies, the selection of pelletisation for residual waste is prevalent across the UK regardless of the variability in the uncertain parameters. Torrefaction of miscanthus is also selected as pretreatment technology; however, this occurs only in 10\% of the scenarios. Similarly, torrefaction of woody biomass is active in $7 \%$ of the scenarios.

\subsection{Detaching BioSNG supply chains from government subsidies}

This section elaborates upon the results presented in Section 5.3 which highlights the role of the feed-in tariff as a dominant factor in the development of BioSNG supply chains. In this case, the objective is to explore what improvements or changes are necessary in order to have a significant production of BioSNG without feed-in tariffs. For this purpose, 7 scenarios were set up based on the parameters investigated in Section 5.3. In the first scenario, Capex was reduced by $30 \%$, for the second scenario, feedstock costs were reduce by $30 \%$, efficiency was increased by $10 \%$ in the third scenario, gas price was increase by $40 \%$ and power price by $35 \%$ for the fourth and fifth scenarios, respectively. The sixth scenario considers the effect of varying Capex, feedstock costs, and efficiency simultaneously, whereas the seventh scenario contemplates the variation of all the parameters. The variation percentages were selected based on the probability distribution functions implemented for the analysis presented in Section 5.3 and can be considered as the best case. In addition, we also explore scenarios in which the renewable obligation certificates scheme (ROCs) does not apply to BioSNG production either. The corresponding results are summarised in Figure 10. 


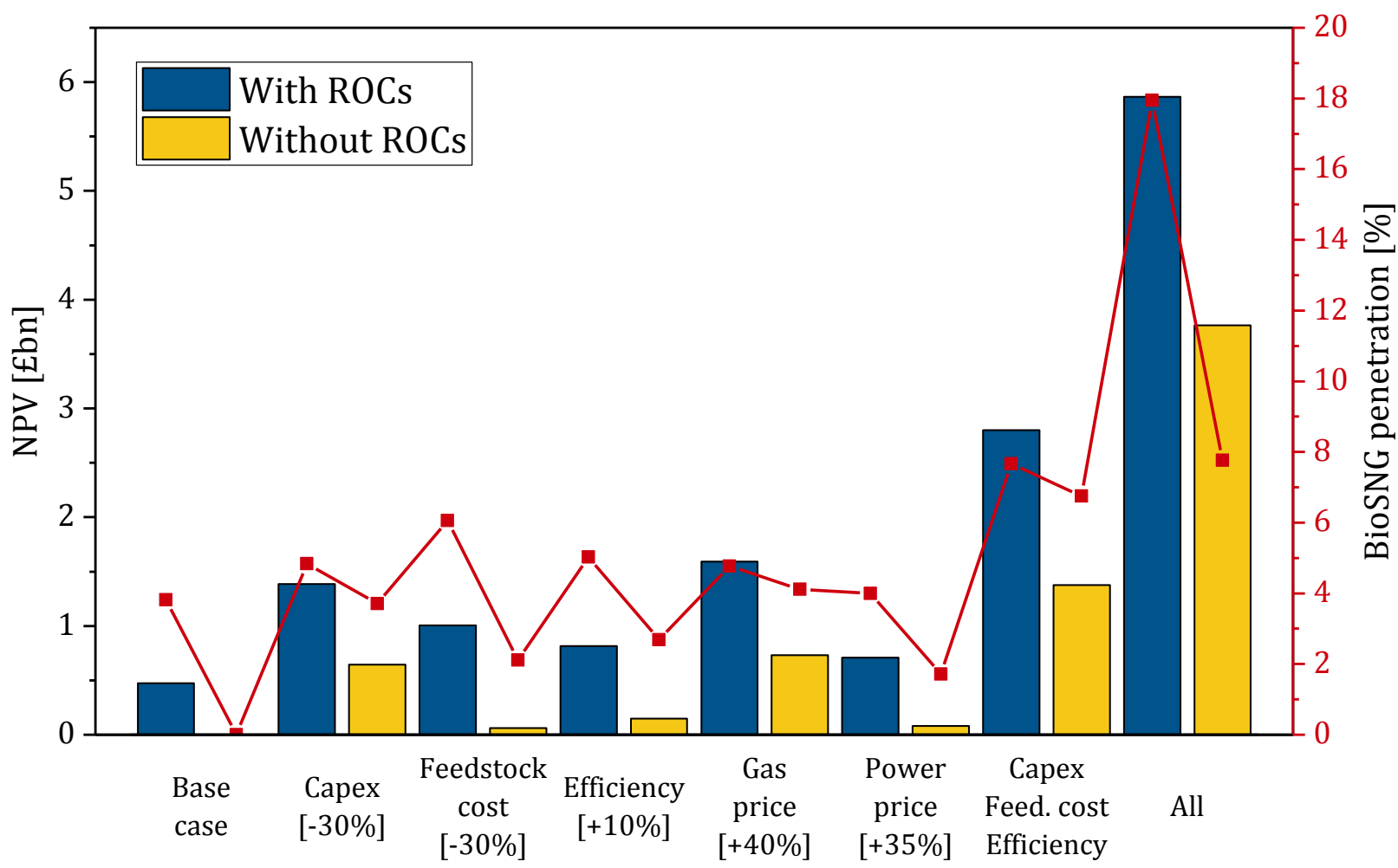

Figure 10. Variation of key parameters and their effect on BioSNG supply levels

805

806

807

808

809

810

811

812

813

814

815

816

817

818

819

820

The blue columns correspond to scenarios in which ROCs are included, whereas the yellow columns correspond to scenarios in which ROCs are no considered. The base case was included for comparison purposes. It can be seen that without feed-in tariff but considering ROC, the results for the base case show a NPV of $£ 0.5$ billion with a BioSNG supply of 3.8\%. In this case, the production of BioSNG is based exclusively on straw and waste. On the other hand, if subsidies are completely eliminated, i.e. "Without ROCs", the development of BioSNG is not attainable. In the case that capital expenses can be reduced by $30 \%$ from what it is reported in literature, it is possible to have a BioSNG supply of 4.8 and $3.7 \%$ with NPVs of $£ 1.4$ billion and $£ 0.6$ billion for scenarios with and without ROCs, respectively. Straw and waste are the only feedstocks harvested for this scenario. A reduction in feedstock costs encourages higher production of BioSNG if ROCs are included achieving a supply of $6 \%$. This is due to the inclusion of woody biomass as part of the feedstock mix. Nonetheless, the NPV is comparatively low to the case with reduced Capex. If all sources of subsidisation are eliminated, a reduction in feedstock costs results in a BioSNG supply of $2.1 \%$ with a low NPV of $£ 0.06$ billion. Increasing the efficiency of the gasification process encourages the inclusion of woody biomass as an additional feedstock 
821 in comparison to the base case. By including ROCs, the BioSNG increases to 5.0\% from the

822 base case. If ROCs are not included, the supply drops to $2.7 \%$. On the side of the market, an 823 increase of $40 \%$ of the gas price from the average projections reported by the UK National 824 Grid [83] will allow a BioSNG supply of $4.8 \%$ and $4.1 \%$ for scenarios with ROCs and without ROCs, respectively. The impact of increasing 35\% the price of electricity from the

826

827

828

829

830

831

832

833

834

835

836

837

838

839

840

841

842

843

844

845

846

847

848

849

850 average forecast is reflected in a supply of 4.0\%, however, if ROCs are not included, the NPV is markedly affected, and the BioSNG supply drops to $1.7 \%$. The independent variation of Capex, feedstock costs, and efficiency does not yield a significant large-scale development of BioSNG. However, the aggregate effect of these parameters results in a substantial BioSNG supply of $7.7 \%$ and a NPV of $£ 2.8$ billion, when ROCs are included. Moreover, without ROCs, it is possible to reach a supply of $6.8 \%$ with a corresponding NPV of $£ 1.4$ billion. Nonetheless, achieving improvements in these parameters of such a magnitude can be unrealistic. Finally, a high BioSNG supply, comparable to scenarios with feed-in tariff, can be obtained only if all the parameters change simultaneously. In this case, by including ROCs, the supply reaches $17.9 \%$ with an NPV of $€ 5.9$ billion, whereas a supply of $7.8 \%$ and an NPV of $£ 7.8$ billion is achieved without subsidies.

\section{Concluding remarks}

A new path for BioSNG production has been included in a mathematical framework for strategic design of BioSNG supply chains presented previously by the authors. This path consists of pretreatment technologies, for generation of intermediate products, and upgrading facilities for final processing. The results show that when pretreatment technologies are considered, the profitability increases by $16 \%$ in comparison to a scenario in which the production of BioSNG is carried out only in integrated facilities. Regarding the cost structure, feedstock purchases continue to be the major component cost, with investments in facilities in second place. Moreover, the operating costs related to transportation are almost double the operating costs of the facilities. In terms of transportation modes, rail is preferred over trucks, delivering around $71 \%$ of the feedstocks and intermediate products. Regarding feedstocks, miscanthus cultivation is the main source of biomass since it contributes with $65.1 \%$ of the total BioSNG production. Only torrefaction for miscanthus and pelletisation for residual waste were selected as 
851 pretreatment technologies, the results suggest that pyrolysis-based technologies are not competitive

A parametric analysis revealed that although the inclusion of pretreatment technologies improve considerably the economic performance, their impact is not enough to detach the development from government subsidisation which influences tremendously the possibility of a large scale deployment. At low subsidisation levels, the production of BioSNG is mostly based on pelletisation of residual waste. This result indicates that the early stages of a development of a BioSNG supply chain can be based on residual waste since this feedstock can be used at maximum availability with relatively low levels of subsidisation. Nonetheless, the supply of BioSNG is relatively low in comparison to the gas demand. An increment in subsidisation levels is necessary to achieve higher supply of BioSNG. Accordingly, a critical tariff of $£ 40 / \mathrm{MWh}$ has been identified which triggers the cultivation of miscanthus making possible to achieve a supply of $\sim 20 \%$. Lower tariffs can severely discourage the development of BioSNG supply chains.

Moreover, a GSA was carried out in order to simultaneously address the impact of uncertainty in 6 parameters: technology efficiency, gas price, power price, capital investments, subsidisation levels, and feedstock costs. It was demonstrated that miscanthus cultivation and woody biomass utilisation are strongly dependant on the subsidisation levels which also reflects on the general economic performance. Residual waste and straw, on the other hand, showed a balanced dependency with other factors such as capital investments and feedstock costs. Despite the variability in the input data, residual waste was consistently selected for production of BioSNG. Straw and woody biomass come in second and third place, respectively. Miscanthus showed a low rate of usage in comparison to the other three feedstocks, and therefore the installation of integrated facilities is affected. Among pretreatment technologies, pyrolysis (FBRP and RCRP) is not competitive with technologies such as pelletisation which is selected in most of the scenarios to process residual waste. Torrefaction is installed in some scenarios to process miscanthus and in some cases woody biomass. The results from the sensitivity analysis confirm that the cultivation of miscanthus is fundamental for the development of BioSNG supply chains but it is also highly susceptible to favourable subsidisation schemes. 
Finally, a scenario-based analysis was presented in order to shed light on necessary technical or market-related changes that would allow to decouple the development of a BioSNG supply chain in the UK from government subsidies. The results show that in order to achieve significant supply rates of BioSNG without government subsidies, it is required not only important reductions on capital expenses and feedstock costs as well as improvement of technology efficiency, but also favourable market prices of gas and electricity. The confluence of these factors seems improbable making the design of appropriate subsidisation schemes critical for large-scale sustainable developments.

\section{Acknowledgements}

The authors would like to thank Dr. Astley Hastings from University of Aberdeen for supplying valuable information for the case studies, and Dr. Sergei Kucherenko and Yemi Zaccheus for the invaluable input in the implementation of the global sensitivity analysis. Finally, Mr. Calderón gratefully acknowledges the financial support from the Colombian Science Council (COLCIENCIAS).

\section{References}

[1] Office of Gas and Electricity Markets (Ofgem), Non-domestic renewable heat incentive (RHI) guidance volume one: Eligibility and how to apply, London, 2014. https://www.ofgem.gov.uk/ofgem-publications/89305/final3guidancevolumeoneaugust2014publication.pdf.

[2] D.M. Reiner, Learning through a portfolio of carbon capture and storage demonstration projects, Nat. Energy. 1 (2016) 15011. doi:10.1038/nenergy.2015.11.

[3] P.-J. Ribeyron, Crystalline silicon solar cells: Better than ever, Nat. Energy. 2 (2017) 17067. doi:10.1038/nenergy.2017.67.

[4] R.C. Armstrong, C.D. Wolfram, K.P. de Jong, R. Gross, N.S. Lewis, B. Boardman, A.J. Ragauskas, K. Ehrhardt-Martinez, G. Crabtree, M. V. Ramana, The frontiers of energy, Nat. Energy. 1 (2016) 15020. doi:10.1038/nenergy.2015.20.

[5] European Environment Agency (EEA), Greenhouse gas emissions from transport, 2016. https://www.eea.europa.eu/data-and-maps/indicators/transport-emissionsof-greenhouse-gases/transport-emissions-of-greenhouse-gases-6.

[6] Y. Sun, J. Cheng, Hydrolysis of lignocellulosic materials for ethanol production: a 
review, Bioresour. Technol. 83 (2002) 1-11.

http://www.ncbi.nlm.nih.gov/pubmed/12058826.

[7] A.V. Bridgwater, Review of fast pyrolysis of biomass and product upgrading, Biomass and Bioenergy. 38 (2012) 68-94. doi:10.1016/j.biombioe.2011.01.048.

[8] M.I. Jahirul, M.G. Rasul, A.A. Chowdhury, N. Ashwath, Biofuels production through biomass pyrolysis- A technological review, Energies. 5 (2012) 4952-5001. doi:10.3390/en5124952.

[9] M. Balat, Production of bioethanol from lignocellulosic materials via the biochemical pathway: A review, Energy Convers. Manag. 52 (2011) 858-875. doi:10.1016/j.enconman.2010.08.013.

[10] I.B. Banković-Ilić, O.S. Stamenković, V.B. Veljković, Biodiesel production from nonedible plant oils, Renew. Sustain. Energy Rev. 16 (2012) 3621-3647. doi:10.1016/j.rser.2012.03.002.

[11] S. Burnley, R. Phillips, T. Coleman, T. Rampling, Energy implications of the thermal recovery of biodegradable municipal waste materials in the United Kingdom, Waste Manag. 31 (2011) 1949-59. doi:10.1016/j.wasman.2011.04.015.

[12] VGB PowerTech, Investment and operation cost figures - Generation portfolio, Essen, 2011. http://www.eurelectric.org/Download/Download.aspx?DocumentFileID=72142.

[13] ECN, Phyllis - database for biomass and waste, (2007). http://www.ecn.nl/phyllis2 (accessed May 12, 2017).

[14] A.I.P. Magalhães, D. Petrovic, A.L. Rodriguez, Z.A. Putra, G. Thielemans, Technoeconomic assessment of biomass pre-conversion of biomass-to-liquids line-up, Biofuels, Bioprod. Biorefining. 3 (2009) 584-600. doi:10.1002/bbb.

[15] C.N. Hamelinck, R.A.A. Suurs, A.P.C. Faaij, International bioenergy transport costs and energy balance, Biomass and Bioenergy. 29 (2005) 114-134. doi:10.1016/j.biombioe.2005.04.002.

[16] A. Uslu, A.P.C. Faaij, P.C.A. Bergman, Pre-treatment technologies, and their effect on international bioenergy supply chain logistics. Techno-economic evaluation of torrefaction, fast pyrolysis and pelletisation, Energy. 33 (2008) 1206-1223. doi:10.1016/j.energy.2008.03.007.

[17] J.A. Ruiz, M.C. Juárez, M.P. Morales, P. Muñoz, M.A. Mendívil, Biomass gasification for electricity generation: Review of current technology barriers, Renew. Sustain. Energy Rev. 18 (2013) 174-183. doi:10.1016/j.rser.2012.10.021.

[18] P. Gilbert, C. Ryu, V. Sharifi, J. Swithenbank, Effect of process parameters on pelletisation of herbaceous crops, Fuel. 88 (2009) 1491-1497.

doi:10.1016/j.fuel.2009.03.015. 
972

973

974

975

976

977

978

979

980 981

[19] B. Batidzirai, Design of sustainable biomass value chains: Optimising the supply logistics and use of biomass over time, PhD Thesis, Utrecht University, 2013. http://dspace.library.uu.nl/handle/1874/287564.

[20] M. Balat, M. Balat, E. Kirtay, H. Balat, Main routes for the thermo-conversion of biomass into fuels and chemicals. Part 1: Pyrolysis systems, Energy Convers. Manag. 50 (2009) 3147-3157. doi:10.1016/j.enconman.2009.08.014.

[21] M. Larsson, M. Görling, S. Grönkvist, P. Alvfors, Bio-methane upgrading of pyrolysis gas from charcoal production, Sustain. Energy Technol. Assessments. 3 (2013) 6673. doi:10.1016/j.seta.2013.07.001.

[22] K.S. Ng, J. Sadhukhan, Process integration and economic analysis of bio-oil platform for the production of methanol and combined heat and power, Biomass and Bioenergy. 35 (2011) 1153-1169. doi:10.1016/j.biombioe.2010.12.003.

[23] C. Couhert, S. Salvador, J.-M. Commandré, Impact of torrefaction on syngas production from wood, Fuel. 88 (2009) 2286-2290. doi:10.1016/j.fuel.2009.05.003.

[24] F. Mafakheri, F. Nasiri, Modeling of biomass-to-energy supply chain operations: Applications, challenges and research directions, Energy Policy. 67 (2014) 116-126. doi:10.1016/j.enpol.2013.11.071.

[25] M.J.C. van der Stelt, H. Gerhauser, J.H.A. Kiel, K.J. Ptasinski, Biomass upgrading by torrefaction for the production of biofuels: A review, Biomass and Bioenergy. 35 (2011) 3748-3762. doi:10.1016/j.biombioe.2011.06.023.

[26] M. Gassner, F. Maréchal, Thermo-economic process model for thermochemical production of Synthetic Natural Gas (SNG) from lignocellulosic biomass, Biomass and Bioenergy. 33 (2009) 1587-1604. doi:10.1016/j.biombioe.2009.08.004.

[27] L. Tock, M. Gassner, F. Maréchal, Thermochemical production of liquid fuels from biomass: Thermo-economic modeling, process design and process integration analysis, Biomass and Bioenergy. 34 (2010) 1838-1854.

doi:10.1016/j.biombioe.2010.07.018.

[28] R.P. Anex, A. Aden, F.K. Kazi, J. Fortman, R.M. Swanson, M.M. Wright, J.A. Satrio, R.C. Brown, D.E. Daugaard, A. Platon, G. Kothandaraman, D.D. Hsu, A. Dutta, Technoeconomic comparison of biomass-to-transportation fuels via pyrolysis, gasification, and biochemical pathways, Fuel. 89 (2010) S29-S35. doi:10.1016/j.fuel.2010.07.015.

[29] V. Pham, M. El-Halwagi, Process synthesis and optimization of biorefinery configurations, AIChE J. 58 (2012) 1212-1221. doi:10.1002/aic.12640.

[30] M. Gassner, F. Maréchal, Thermo-economic optimisation of the polygeneration of synthetic natural gas (SNG), power and heat from lignocellulosic biomass by gasification and methanation, Energy Environ. Sci. 5 (2012) 5768-5789. doi:10.1039/c1ee02867g. 
[31] R.C. Baliban, J.A. Elia, C.A. Floudas, B. Gurau, M.B. Weingarten, S.D. Klotz, Hardwood Biomass to Gasoline, Diesel, and Jet Fuel : 1. Process Synthesis and Global Optimization of a Thermochemical Refinery, Energy \& Fuels. 27 (2013) 4302-4324.

[32] B.H. Gebreslassie, M. Slivinsky, B. Wang, F. You, Life cycle optimization for sustainable design and operations of hydrocarbon biorefinery via fast pyrolysis, hydrotreating and hydrocracking, Comput. Chem. Eng. 50 (2013) 71-91. doi:10.1016/j.compchemeng.2012.10.013.

[33] A. Kelloway, P. Daoutidis, Process synthesis of biorefineries: Optimization of biomass conversion to fuels and chemicals, Ind. Eng. Chem. Res. 53 (2014) 5261-5273. doi:10.1021/ie4018572.

[34] A. Zamboni, S. Giarola, F. Bezzo, Towards Second Generation Bioethanol : Supply Chain Design and Capacity Planning, Comput. Aided Chem. Eng. 29 (2011) 16931697. doi:10.1016/B978-0-444-54298-4.50117-3.

[35] O. Akgul, N. Shah, L.G. Papageorgiou, An optimisation framework for a hybrid first/second generation bioethanol supply chain, Comput. Chem. Eng. 42 (2012) 101-114. doi:10.1016/j.compchemeng.2012.01.012.

[36] F.D. Mele, A.M. Kostin, G. Guillén-Gosálbez, L. Jiménez, Multiobjective model for more sustainable fuel supply chains. A case study of the sugar cane industry in argentina, Ind. Eng. Chem. Res. 50 (2011) 4939-4958. doi:10.1021/ie101400g.

[37] H. Paulo, X. Azcue, A.P. Barbosa-Póvoa, S. Relvas, Supply chain optimization of residual forestry biomass for bioenergy production: The case study of Portugal, Biomass and Bioenergy. 83 (2015) 245-256. doi:10.1016/j.biombioe.2015.09.020.

[38] M.M. Wright, R.C. Brown, Distributed processing of biomass to bio-oil for subsequent production of Fischer-Tropsch liquids, Biofuels, Bioprod. Biorefining. 2 (2008) 229238. doi:10.1002/bbb.

[39] A.J. Dunnett, C.S. Adjiman, N. Shah, A spatially explicit whole-system model of the lignocellulosic bioethanol supply chain: an assessment of decentralised processing potential, Biotechnol. Biofuels. 1 (2008) 13. doi:10.1186/1754-6834-1-13.

[40] I.M. Bowling, J.M. Ponce, M.M. El-Halwagi, Facility Location and Supply Chain Optimization for a Biorefinery, Ind. Eng. Chem. Res. 50 (2011) 6276-6286. doi:10.1021/ie101921y.

[41] J. Kim, M.J. Realff, J.H. Lee, Simultaneous design and operation decisions for biorefinery supply chain networks: Centralized vs. distributed system, IFAC Proc. Vol. 9 (2010) 73-78. doi:10.3182/20100705-3-BE-2011.0063.

[42] J. Kim, M.J. Realff, J.H. Lee, C. Whittaker, L. Furtner, Design of biomass processing network for biofuel production using an MILP model, Biomass and Bioenergy. 35 (2011) 853-871. doi:10.1016/j.biombioe.2010.11.008. 
[43] F. You, B. Wang, Life cycle optimization of biomass-to-liquid supply chains with distributed - centralized processing networks, Ind. Eng. Chem. Res. 50 (2011) 10102-10127.

[44] A.J. Calderón, P. Agnolucci, L.G. Papageorgiou, An optimisation framework for the strategic design of synthetic natural gas (BioSNG) supply chains, Appl. Energy. 187 (2017) 929-955. doi:10.1016/j.apenergy.2016.10.074.

[45] Eurostat, NUTS - Nomenclature of territorial units for statistics, (2013). http://ec.europa.eu/eurostat/web/nuts/overview.

[46] E4tech, The potential for bioSNG production in the UK, London, 2010. http://www.nnfcc.co.uk/tools/potential-for-biosng-production-in-the-uk-nnfcc-10008.

[47] Progressive Energy \& CNG Services, BioSNG feasibility study. Establishment of a regional project, UK, 2010. http://www.cngservices.co.uk/assets/Bio-SNGFeasibility-Study.pdf.

[48] A. van der Drift, R.W.. Zwart, B.. Vreugdenhil, L.P.. Bleijendaal, Comparing the options to produce SNG from biomass, in: 18th Eur. Biomass Conf. Exhib., Lyon, France, 2010: pp. 3-7.

[49] C.M. van der Meijden, H.J. Veringa, L.P.L.M. Rabou, The production of synthetic natural gas (SNG): A comparison of three wood gasification systems for energy balance and overall efficiency, Biomass and Bioenergy. 34 (2010) 302-311. doi:10.1016/j.biombioe.2009.11.001.

[50] National Grid, Gas network innovation competition: Project NGGDGN01, 2014. http://www.smarternetworks.org/Files/BioSNG_Demonstration_Plant_1312031517 50.pdf.

[51] A. Tremel, M. Gaderer, H. Spliethoff, Small-scale production of synthetic natural gas by allothermal biomass gasification, Int. J. Energy Res. 37 (2013) 1318-1330. doi:10.1002/er.2933.

[52] K. Svoboda, M. Pohořelý, M. Hartman, J. Martinec, Pretreatment and feeding of biomass for pressurized entrained flow gasification, Fuel Process. Technol. 90 (2009) 629-635. doi:10.1016/j.fuproc.2008.12.005.

[53] ESRI, ArcGIS Desktop: Release 10.2.2. Redlands, CA: Environmental Systems Research Institute, 2014. http://www.esri.com/software/arcgis/arcgis-for-desktop.

[54] Energy Information Administration (EIA), International Energy Statistics, (2012). http://www.eia.gov/cfapps/ipdbproject/IEDIndex3.cfm (accessed June 1, 2014).

[55] European Environmental Agency (EEA), How much bioenergy can Europe produce without harming the environment?., Copenhagen, 2006. http://www.eea.europa.eu/publications/eea_report_2006_7. 
1064

1065

1066

1067

1068

1069

1070

1071

1072

1073

1074

1075

1076

1077

1078

1079

1080

1081

1082

1083

1084

1085

1086

1087

1088

1089

1090

1091

1092

1093

1094

1095

1096

1097

[56] H. McKay, J.B. Hudson, R.J. Hudson, Woodfuel resource in Britain: main report, 2003. http://www.biomassenergycentre.org.uk/pls/portal/docs/PAGE/RESOURCES/REF_ LIB_RES/PUBLICATIONS/RESOURCE AVAILABILITY/WOODFUEL RESOURCE IN BRITAIN FILE15006.PDF.

[57] E4tech, Biomass prices in the heat and electricity sectors in the UK, 2010. http://www.rhincentive.co.uk/library/regulation/100201Biomass_prices.pdf.

[58] Forestry Research, Woodfuel Resource: Study into the potentially available woodfuel resource of Great Britain, (2002). https://www.eforestry.gov.uk/woodfuel/pages/home.jsp (accessed May 15, 2014).

[59] Department for Environment Food \& Rural Affairs (DEFRA), Experimental Statistics: Area of crops grown for bioenergy in England and the UK: 2008 - 2012, 2014. https://www.gov.uk/government/uploads/system/uploads/attachment_data/file/2 89168/nonfood-statsnotice2012-12mar14.pdf.

[60] Department for Environment Food \& Rural Affairs (DEFRA), UK Biomass Strategy, London, 2007.

http://www.biomassenergycentre.org.uk/pls/portal/docs/PAGE/RESOURCES/REF_ LIB_RES/PUBLICATIONS/UKBIOMASSSTRATEGY.PDF.

[61] Department for Environment Food \& Rural Affairs (DEFRA), Waste strategy for England 2007, London, 2007. https://www.gov.uk/government/publications/wastestrategy-for-england-2007 (accessed October 2, 2013).

[62] WRAP, The composition of municipal solid waste in Wales, 2010. http://www.wrapcymru.org.uk/sites/files/wrap/Wales_compositional_analysis_rep ort_2_.9076.pdf (accessed October 2, 2013).

[63] Welsh Assembly Government, The overarching waste strategy document for wales: Towards zero waste, Cardiff, 2010. http://wales.gov.uk/docs/desh/publications/100621wastetowardszeroen.pdf.

[64] Welsh Assembly Government, Survey of Industrial \& Commercial waste generated in Wales 2012, Cardiff, 2012. https://www.naturalresources.wales/media/1995/survey-of-industrial-andcommercial-waste-generated-in-wales-2012pdf.pdf.

[65] Welsh Assembly Government, Consultation document towards zero waste one wales: One planet, Cardiff, 2013. www.cymru.gov.uk.

[66] The Scottish Government, Scotland's Zero Waste Plan, Edinburgh, 2010. http://www.gov.scot/Resource/0045/00458945.pdf.

[67] Department for Environment Food \& Rural Affairs (DEFRA), Household waste forecasts for England, London, 2013. https://www.gov.uk/government/uploads/system/uploads/attachment_data/file/2 86332/Household_Waste_Forecasts_for_England_Feb13_and_Oct13.pdf. 
[68] Department for Environment Food \& Rural Affairs (DEFRA), Survey of commercial and industrial waste arisings, London, 2011. https://www.gov.uk/government/uploads/system/uploads/attachment_data/file/4 00595/ci-statistics-release.pdf.

[69] Department for Environment Food \& Rural Affairs (DEFRA), Forecasting 2020 waste arisings and treatment capacity, London, 2013. https://www.gov.uk/government/uploads/system/uploads/attachment_data/file/3 64243/forecasting-2020-hertfordshire-analysis-20141016.pdf.

[70] Department for Environment Food \& Rural Affairs (DEFRA), Government review of waste policy in England 2011, London, 2011. doi:10.1016/j.jclepro.2012.11.037.

[71] WRAP, Comparing the cost of alternative waste treatment options, 2013. http://www.wrap.org.uk/sites/files/wrap/Gate_Fees_Report_2013_h \%282\%29.pdf.

[72] A. Hastings, M.J. Tallis, E. Casella, R.W. Matthews, P.A. Henshall, S. Milner, P. Smith, G. Taylor, The technical potential of Great Britain to produce ligno-cellulosic biomass for bioenergy in current and future climates, GCB Bioenergy. 6 (2014) 108-122. doi:10.1111/gcbb.12103.

[73] A. Lovett, G. Sünnenberg, T. Dockerty, The availability of land for perennial energy crops in Great Britain, GCB Bioenergy. 6 (2014) 99-107. doi:10.1111/gcbb.12147.

[74] European Environment Agency (EEA), Estimating the environmentally compatible bioenergy potential from agriculture, Copenhagen, 2007. http://www.eea.europa.eu/publications/technical_report_2007_12 (accessed April $25,2014)$.

[75] A.W. Bauen, A.J. Dunnett, G.M. Richter, A.G. Dailey, M. Aylott, E. Casella, G. Taylor, Modelling supply and demand of bioenergy from short rotation coppice and Miscanthus in the UK, Bioresour. Technol. 101 (2010) 8132-43. doi:10.1016/j.biortech.2010.05.002.

[76] Forestry Commission, National forest inventory Great Britain, (2013). http://www.forestry.gov.uk/.

[77] EDINA Environment Digimap Service, Great Britain 25m [TIFF geospatial data], Scale 1:250000, Tiles: GB, (2008). http://digimap.edina.ac.uk.

[78] M. Materazzi, P. Lettieri, R. Taylor, C. Chapman, Performance analysis of RDF gasification in a two stage fluidized bed-plasma process, Waste Manag. 47 (2016) 256-266. doi:10.1016/j.wasman.2015.06.016.

[79] A. Pirraglia, R. Gonzalez, D. Saloni, Techno-economical analysis of wood pellets production for US manufacturers, BioResources. 5 (2010) 2374-2390. http://ojs.cnr.ncsu.edu/index.php/BioRes/article/view/BioRes_05_4_2374_Pirraglia _GS_Wood_Pellets_Tech_Economics (accessed April 25, 2014). 
[80] Y. Qian, W. Mcdow, The wood pellet value chain. An economic analysis of the wood pellet supply chain from the Southeast United States to European Consumers, Greenville, 2013. http://www.usendowment.org/images/The_Wood_Pellet_Value_Chain_Revised_Fina l.pdf.

[81] Ordnance Survey (OS), MERIDIAN2 [geospatial data], Scale 1:50000, Tiles: GB, (2014). http://www.ordnancesurvey.co.uk/business-andgovernment/products/meridian2.html (accessed March 30, 2015).

[82] National Grid, Gas Ten Year Statement, London, 2013. http://www2.nationalgrid.com/UK/Industry-information/Future-of-Energy/Gasten-year-statement/Archive/.

[83] National Grid, UK Future Energy Secenarios, London, 2013. http://www2.nationalgrid.com/uk/industry-information/future-ofenergy/fes/Documents/.

[84] Office of Gas and Electricity Markets (Ofgem), Renewables Obligation : Guidance for generators, 2014. https://www.ofgem.gov.uk/ofgempublications/87997/renewablesobligation-guidanceforgenerators1june2014.pdf.

[85] Office of Gas and Electricity Markets (Ofgem), Renewables Obligation (RO) buy-out price and mutualisation ceilings for 2017-18, (2017). https://www.ofgem.gov.uk/publications-and-updates/renewables-obligation-robuy-out-price-and-mutualisation-ceilings-2017-18 (accessed March 1, 2017).

[86] I.M. Sobol, Global sensitivity indices for nonlinear mathematical models and their Monte Carlo estimates, Math. Comput. Simul. 55 (2001) 271-280. doi:10.1016/S0378-4754(00)00270-6.

[87] A. Saltelli, M. Ratto, T. Andres, F. Campolongo, J. Cariboni, D. Gatelli, M. Saisana, S. Tarantola, Global Sensitivity Analysis. The Primer, John Wiley \& Sons, Ltd, Chichester, UK, 2007. doi:10.1002/9780470725184.

[88] S. Kucherenko, M. Rodriguez-Fernandez, C. Pantelides, N. Shah, Monte Carlo evaluation of derivative-based global sensitivity measures, Reliab. Eng. Syst. Saf. 94 (2009) 1135-1148. doi:10.1016/j.ress.2008.05.006.

[89] National Grid, Future Energy Scenarios: GB gas and electricity transmission, London, 2016. http://www2.nationalgrid.com/uk/industry-information/future-ofenergy/future-energy-scenarios/.

[90] B. Feil, S. Kucherenko, N. Shah, Comparison of Monte Carlo and Quasi Monte Carlo Sampling Methods in High Dimensional Model Representation, 2009 First Int. Conf. Adv. Syst. Simul. (2009) 12-17. doi:10.1109/SIMUL.2009.34.

[91] G. Li, S.W. Wang, H. Rabitz, Practical approaches to construct RS-HDMR component functions, J. Phys. Chem. A. 106 (2002) 8721-8733. doi:10.1021/jp014567t. 
1173 [92] M.M. Zuniga, S. Kucherenko, N. Shah, Metamodelling with independent and

1174

1175

1176

1177

1178

1179

1180

1181

1182

1183

1184

1185

1186

1187

1188

1189 dependent inputs, Comput. Phys. Commun. 184 (2013) 1570-1580. doi:10.1016/j.cpc.2013.02.005.

[93] S. Kucherenko, O. Zaccheus, SobolGSA Software, (2017). http://www.imperial.ac.uk/process-systems-engineering/research/freesoftware/sobolgsa-software/ (accessed November 1, 2016).

[94] J.G. Rogers, J.G. Brammer, Estimation of the production cost of fast pyrolysis bio-oil, Biomass and Bioenergy. 36 (2012) 208-217. doi:10.1016/j.biombioe.2011.10.028.

[95] H.S. Heo, H.J. Park, J.H. Yim, J.M. Sohn, J. Park, S.S. Kim, C. Ryu, J.K. Jeon, Y.K. Park, Influence of operation variables on fast pyrolysis of Miscanthus sinensis var. purpurascens, Bioresour. Technol. 101 (2010) 3672-3677. doi:10.1016/j.biortech.2009.12.078.

[96] E. Searcy, P. Flynn, E. Ghafoori, A. Kumar, The relative cost of biomass energy transport, Appl. Biochem. Biotechnol. 137-140 (2007) 639-652. doi:10.1007/s12010-007-9085-8. 


\section{List of Tables}

1191

1192 Table 1. Capex, Opex and technical specifications of processing facilities............................... 53

1193 Table 2. Fixed and variable costs for feedstock transportation.................................................. 53

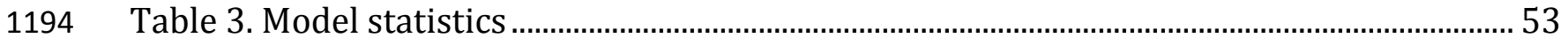

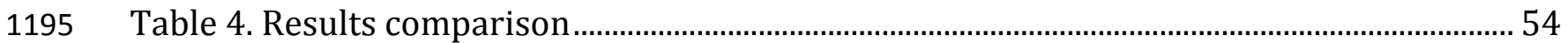

1196

1197 
Table 1. Capex, Opex and technical specifications of processing facilities.

\begin{tabular}{ccccccc} 
& Torrefaction & Pelletisation & RCRP & FBRP & $\begin{array}{c}\text { Allothermal } \\
\text { gasification } \\
\text { (MILENA) }\end{array}$ & $\begin{array}{c}\text { Plasma } \\
\text { gasification }\end{array}$ \\
\hline Feedstock & $\begin{array}{c}\text { Woody } \\
\text { biomass }\end{array}$ & $\begin{array}{c}\text { Woody } \\
\text { biomass }\end{array}$ & $\begin{array}{c}\text { Woody } \\
\text { biomass }\end{array}$ & $\begin{array}{c}\text { Woody } \\
\text { biomass }\end{array}$ & $\begin{array}{c}\text { Woody } \\
\text { biomass }\end{array}$ & Waste \\
Capacity [MW] & 100 & 100 & 100 & 100 & 100 & 100 \\
$\begin{array}{c}\text { Capex [Em] } \\
\text { Fixed cost [Em/y] }\end{array}$ & 25.8 & 17.7 & 16.6 & 30.7 & 116 & 149 \\
$\begin{array}{l}\text { Variable cost } \\
\text { [Em/GWh] }\end{array}$ & 1.0 & 0.9 & 2.0 & 1.3 & 3.0 & 2.8 \\
$\begin{array}{c}\text { Efficiency [\%] } \\
\text { (based on LHV] }\end{array}$ & 93.8 & $1.4 \mathrm{E}-03$ & $4.6 \mathrm{E}-03$ & $2.1 \mathrm{E}-03$ & $3.7 \mathrm{E}-03$ & $2.4 \mathrm{E}-02$ \\
$\begin{array}{l}\text { Heat recovery } \\
\text { efficiency [\%] }\end{array}$ & 0 & 95.0 & 73.6 & 92.4 & 63.8 & 52.0 \\
References & {$[14,19]$} & {$[79,80]$} & {$[8,14,94,9$} & {$[14,43]$} & {$[19,47]$} & $10 \%$ \\
\hline
\end{tabular}

1199

1200

Table 2. Fixed and variable costs for feedstock transportation [96].

\begin{tabular}{ccccc} 
& \multicolumn{2}{c}{ Fixed costs $[£ / \mathrm{GWh}]$} & \multicolumn{2}{c}{ Variable costs $[£ / \mathrm{km}-\mathrm{GWh}]$} \\
\cline { 2 - 5 } & Truck & Rail & Truck & Rail \\
\hline Woody biomass & 821.9 & 1496.3 & 19.1 & 4.6 \\
Waste & 1451.7 & 4679.2 & 39.9 & 7.6 \\
Miscanthus & 1097.9 & 3538.9 & 30.0 & 5.8 \\
Straw & 1088.8 & 3509.4 & 29.8 & 5.7 \\
\hline
\end{tabular}

1201

Table 3. Model statistics

\begin{tabular}{lcc}
\cline { 2 - 3 } & $\begin{array}{c}\text { Without } \\
\text { pretreatment } \\
\text { technologies }\end{array}$ & $\begin{array}{c}\text { With } \\
\text { pretreatment } \\
\text { technologies }\end{array}$ \\
\hline Total number of variables & 16,553 & 71,865 \\
$\quad$ Continuous variables & 13,613 & 53,105 \\
$\quad$ Binary variables & 2,940 & 18,760 \\
Total number of constraints & 12,245 & 68,533 \\
Non zero constraint matrix & 56,589 & 265,231 \\
elements & 183 & 15,247 \\
CPU time [s] & 21,446 & 25,524 \\
Optimal NPV [Em] & & \\
\hline
\end{tabular}

1203

1204

1205

1206 
Table 4. Comparison of scenarios with and without pretreatment technologies

\begin{tabular}{|c|c|c|c|}
\hline Feed-in tariff: $70 £ / M W h$ & $\begin{array}{c}\text { With } \\
\text { pretreatment } \\
\text { technologies }\end{array}$ & $\begin{array}{l}\text { Without } \\
\text { pretreatment } \\
\text { technologies }\end{array}$ & $\begin{array}{c}\text { Variation } \\
\text { [\%] }\end{array}$ \\
\hline Net Present Value [Em] & 25,524 & 21,446 & -16.0 \\
\hline Capex $[\mathrm{Em}]$ & 17,461 & 20,404 & 16.9 \\
\hline Integrated plants & 8,079 & 17,044 & 111.0 \\
\hline Pretreatment plants & 1,516 & - & - \\
\hline Upgrading plants & 4,506 & - & - \\
\hline BioSNG transportation & 408 & 408 & -0.1 \\
\hline Energy crops & 2,952 & 2,952 & 0.0 \\
\hline Opex [Em] & 36,866 & 41,126 & 11.6 \\
\hline FeedCosts & 24,328 & 24,214 & -0.5 \\
\hline ProdCosts & 4,190 & 7,590 & 81.1 \\
\hline Transportation [Em] & 8,349 & 9,322 & 11.7 \\
\hline $\begin{array}{l}\text { - Feedstocks and } \\
\text { intermediate products }\end{array}$ & 6,976 & 7,953 & 14.0 \\
\hline - BioSNG & 1,372 & 1,369 & -0.2 \\
\hline Income [Em] & 27,332 & 27,790 & 1.7 \\
\hline BioSNG sales & 19,296 & 19,505 & 1.1 \\
\hline Power sales & 8,036 & 8,284 & 3.1 \\
\hline Incentives [Em] & 70,222 & 71,172 & 1.4 \\
\hline Feed-in tariff & 61,550 & 62,229 & 1.1 \\
\hline$R O C$ & 8,672 & 8,944 & 3.1 \\
\hline Taxes $[\mathrm{Em}]$ & 17,702 & 15,986 & -9.7 \\
\hline Cash Flow [fm] & 42,985 & 41,849 & -2.6 \\
\hline \multicolumn{4}{|l|}{ Production } \\
\hline BioSNG [GWh/year] & 104,052 & 105,070 & 1.0 \\
\hline Power [GWh/year] & 12,862 & 13,234 & 2.9 \\
\hline $\begin{array}{l}\text { Woody biomass } \\
\text { [kTon/year] }\end{array}$ & 4,975 & 4,975 & 0.0 \\
\hline Miscanthus [kTon/year] & 31,696 & 31,563 & -0.4 \\
\hline Straw [kTon/year] & 3,750 & 3,750 & 0.0 \\
\hline Waste [kTon/year] & 15,191 & 15,216 & 0.2 \\
\hline BioSNG penetration [\%] & 21.22 & 21.43 & 1.0 \\
\hline \multicolumn{4}{|l|}{ Integrated plants [MW] } \\
\hline $\begin{array}{l}\text { Woody biomass } \\
\text { [kTon/year] }\end{array}$ & 2,645 & 2,645 & 0.0 \\
\hline Miscanthus & 12,692 & 16,637 & 31.1 \\
\hline Straw & 1,784 & 1,784 & 0.0 \\
\hline Waste & - & 7,535 & - \\
\hline \multicolumn{4}{|l|}{ Pretreatment plants [MW] } \\
\hline Pelletisation - Waste & 7,500 & - & - \\
\hline Torrefaction - Miscanthus & 3,973 & - & - \\
\hline Upgrading plants [MW] & 9,791 & - & - \\
\hline
\end{tabular}


1208 